BNL-107509-2015-JA

Subscriber access provided by Columbia Univ Libraries

Article

\title{
Two-Step Nucleation and Growth of InP Quantum Dots via Magic-Sized Cluster Intermediates
}

\author{
Dylan C Gary, Maxwell W. Terban, Simon J. L. Billinge, and Brandi M. Cossairt
}

Chem. Mater., Just Accepted Manuscript • DOI: 10.1021/acs.chemmater.5b00286 • Publication Date (Web): 30 Jan 2015

Downloaded from http://pubs.acs.org on February 10, 2015

\section{Just Accepted}

"Just Accepted" manuscripts have been peer-reviewed and accepted for publication. They are posted online prior to technical editing, formatting for publication and author proofing. The American Chemical Society provides "Just Accepted" as a free service to the research community to expedite the dissemination of scientific material as soon as possible after acceptance. "Just Accepted" manuscripts appear in full in PDF format accompanied by an HTML abstract. "Just Accepted" manuscripts have been fully peer reviewed, but should not be considered the official version of record. They are accessible to all readers and citable by the Digital Object Identifier (DOI®). "Just Accepted" is an optional service offered to authors. Therefore, the "Just Accepted" Web site may not include all articles that will be published in the journal. After a manuscript is technically edited and formatted, it will be removed from the "Just Accepted" Web site and published as an ASAP article. Note that technical editing may introduce minor changes to the manuscript text and/or graphics which could affect content, and all legal disclaimers and ethical guidelines that apply to the journal pertain. ACS cannot be held responsible for errors or consequences arising from the use of information contained in these "Just Accepted" manuscripts. 


\section{INTRODUCTION}

Semiconductor nanocrystals (quantum dots, QDs) have recently entered the marketplace for LED downconversion in display applications. ${ }^{1}$ The QDs used in these devices enable the generation of a wider colour gamut than traditional displays because of their narrow emission line widths, which are tuneable across the visible region of the electromagnetic spectrum through the quantum confinement effect. The material of choice for these applications has been cadmium selenide (CdSe) QDs because the techniques developed for the colloidal synthesis of CdSe yield highly crystalline material with narrow size distributions across a wide range of sizes. ${ }^{2}$

Although CdSe QDs are already utilized in displays, the toxicity of cadmium remains a health and environmental concern as well as a barrier to further commercialization. ${ }^{3}$ Indium phosphide (InP) has been identified as an ideal candidate for cadmium-free QD technology. ${ }^{4}$ InP has a direct bandgap in the visible region, a Bohr exciton radius of $11 \mathrm{~nm}$, and preliminary studies suggest that $\mathrm{InP} / \mathrm{ZnS}$ QD cytotoxicity is low enough to be utilized for in vivo biological imaging. ${ }^{4-7}$ While current state of the art syntheses of $\mathrm{InP}^{8}$ lag behind those of $\mathrm{CdSe}^{2}$ in terms of the particle spectral line widths, Cui et al. have demonstrated through solution phase photon correlation Fourier spectroscopy that the intrinsic luminescence line width of InP QDs is comparable to that of CdSe QDs. ${ }^{9}$ These results confirm the potential for narrow emission profiles from InP QDs and highlight the need to minimize sample inhomogeneity through an improved synthesis. In order to rationally design such a synthesis, a better understanding of the underlying mechanisms for the reactions from molecular precursors to nanocrystals must be acquired.

Previous attempts to improve the quality of InP QDs through colloidal synthesis have focused primarily on the precursor conversion event. ${ }^{10-12}$ The most common phosphorus precursor reported for the colloidal synthesis of InP QDs is tris(trimethylsilyl)phosphine $\left(\mathrm{P}\left(\mathrm{SiMe}_{3}\right)_{3}\right)^{13-20}$ The extreme reactivity of this silylphosphine leads to a situation where molecular precursors are completely consumed within seconds of a hot-injection. In this scenario, all InP monomers produced from molecular precursors are depleted during the nucleation event. This rapid nucleation precludes size-selective growth, which requires InP monomer reserves. ${ }^{21,22}$ Additionally, $\mathrm{P}\left(\mathrm{SiMe}_{3}\right)_{3}$ has been shown to promote detrimental side reactions with carboxylic acids, which are typically employed as ligands in such syntheses. ${ }^{14,16}$ A recent report by our lab demon- 
strated that tris(triphenylsilyl)phosphine $\left(\mathrm{P}\left(\mathrm{SiPh}_{3}\right)_{3}\right)$ can be employed as a phosphorus precursor for InP QDs. ${ }^{12}$ By employing $\mathrm{P}\left(\mathrm{SiPh}_{3}\right)_{3}$ to provide monomer reserves in tandem with $\mathrm{P}\left(\mathrm{SiMe}_{3}\right)_{3}$ to induce rapid nucleation in a single injection, a synergistic effect was achieved where nucleation and growth can be independently tuned through control of stoichiometry. While this approach afforded a wide window of growth from a single injection, it did not improve the final size distribution relative to syntheses that employed $\mathrm{P}\left(\mathrm{SiMe}_{3}\right)_{3}$ as the sole phosphorus precursor. These results are contrary to classical nucleation theory and suggest that control of precursor conversion rate alone is not sufficient to obtain a monodisperse sample of InP..$^{21,22}$

The origin for this departure from classical nucleation theory as discussed herein was illuminated by lowering the temperature at which the crystallites grew. When the growth temperature of the reaction was lowered to $120{ }^{\circ} \mathrm{C}$, a peak was observed in the UV-Vis spectrum with a lowest energy electronic transition (LEET) at $386 \mathrm{~nm}$. This feature is precisely reproducible from batch to batch for growth temperatures up to $120{ }^{\circ} \mathrm{C}$, which is indicative of a magic-sized cluster (MSC). MSCs differ from other ultrasmall nanoparticles in that MSCs exhibit remarkable thermodynamic stability relative to similar sizes. ${ }^{23}$ This stability leads to a quantized growth from one family of MSCs to another (heterogeneous growth) rather than continuous growth without any preference for a specific size (homogenous growth), which is observed for larger nanoparticle sizes. ${ }^{24}$ At temperatures of $150{ }^{\circ} \mathrm{C}$ and higher, UV-Vis spectra of timed aliquots revealed heterogeneous growth from MSCs directly to InP QDs with an initial diameter of approximately $3 \mathrm{~nm}$. This change in LEET corresponds to a difference in particle diameter of about 1-2 nm. Such a drastic change in particle size without observation of intermediate sizes suggests that this cluster plays an integral role in the nucleation and growth of colloidal InP QDs from molecular precursors.

Two possible explanations are that nucleation of InP QDs either proceeds via dissolution of MSCs back to monomers followed by a second nucleation event or MSCs aggregate to yield QDs. Either scenario would undermine previous research efforts to synthesize less reactive phosphorus precursors in order to maintain an InP monomer reservoir. In the case of a second nucleation event, precision control of monomer production rates would be difficult or impossible to achieve through finetuning of molecular precursor reactivity when there are multiple reaction pathways for monomer production. Nucleation through aggregation would impede efforts to separate nucleation and growth as monomers from precursor conversion could either grow on existing QDs or form MSCs to nucleate new QDs. It is evident that these MSCs play a critical role in the nucleation and growth of InP and warrant further investigation.

A variety of binary semiconductor MSCs have been investigated including lead selenide $(\mathrm{PbSe}),{ }^{25}$ zinc selenide $(\mathrm{ZnSe})^{26}$, zinc telluride $(\mathrm{ZnTe})^{27,28}$, cadmium sulfide $(\mathrm{CdS})^{29}$, cadmium selenide $(\mathrm{CdSe})^{24,30-34}$, cadmium tellu- ride $(\mathrm{CdTe})^{32}$, and cadmium phosphide $\left(\mathrm{Cd}_{3} \mathrm{P}_{2}\right)^{35}$. This class of nanocluster has shown utility for applications ranging from white $\mathrm{LEDs}^{24}$, blue LEDs ${ }^{31}$, room temperature nucleants for nanoplatelets ${ }^{36}$, to in vivo biological imaging $^{25}$. CdSe clusters in particular have proven to be a versatile starting material for a variety of nanostructures such as rods, rice, tadpoles ${ }^{37}$, ribbons ${ }^{38}$, nanosheets ${ }^{39}$, and quantum belts ${ }^{40}$.

While there have been numerous studies of II-VI MSCs, there has been, to date, only two reports of III-V MSCs to the best of our knowledge. ${ }^{41,42}$ In the first study by Xie et al. two MSCs of InAs were observed to precede the formation of InAs QDs. In the second study, Xie et al. employed InP MSCs as a convenient probe to study the kinetics of InP synthesis from molecular precursors. These clusters were chosen as the ideal end product due to their stability across a wide range of growth temperatures and precursor concentrations as well as having a distinct optical absorption spectrum in the visible region. The UV-Vis spectrum of the InP MSCs that we observe is identical to that reported by Xie et al. It is peculiar, given the unique properties exhibited by MSCs for other materials as well as their utility as precursors for a range of nanostructures, that this III-V cluster has not been investigated beyond the kinetics of its formation. One report by Yang et al. may have already demonstrated such utility. ${ }^{8}$ In this study, $\mathrm{P}\left(\mathrm{SiMe}_{3}\right)_{3}$ was injected into $\mathrm{In}\left(\mathrm{O}_{2} \mathrm{C}\left(\mathrm{CH}_{2}\right)_{12} \mathrm{CH}_{3}\right)$ (indium myristate, $\left.\operatorname{In}(\mathrm{MA})_{3}\right)$ at room temperature under inert atmosphere to preform yellow InP "nuclei" that were not characterized. These nuclei were superior to molecular precursors for synthesizing high quality InP/ZnS QDs.

Scheme 1. Reaction pathways from molecular precursors to InP MSCs and QDs.

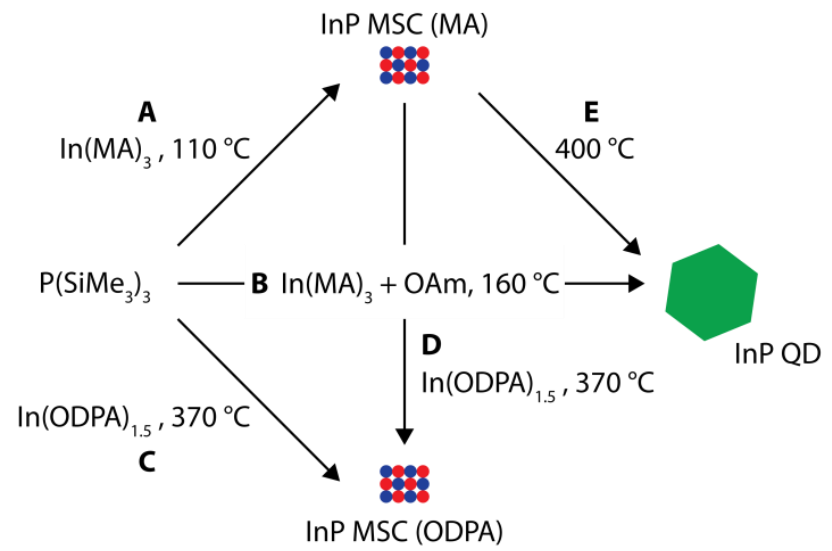

In this study we report that the carboxylate-capped InP MSCs first reported by Xie et al. are important intermediates in the growth of InP QDs from molecular precursors (Scheme ${ }_{1} \mathrm{~A}$ ). The stability of the MSCs were found to be highly dependent on the presence of additives such as amines (Scheme $1 \mathrm{~B}$ ), which have typically been employed in such syntheses to lower the temperature necessary for QD growth. ${ }^{15,19}$ The thermodynamic stability, absorption spectrum, and core structure of the MSC was found to be dependent on the choice of ligand set (Scheme $\left.{ }_{1} C, D\right)$. The utility of the MSC as a single source precursor (SSP) was 
evaluated by hot-injection of isolated clusters into a noncoordinating solvent (Scheme $1 \mathrm{E}$ ). The simplicity of using MSCs, which are isolable on the gram scale, as SSPs has enabled us to better understand the nucleation and growth of InP QDs.

\section{RESULTS AND DISCUSSION}

We have observed the formation of InP clusters with a LEET at $386 \mathrm{~nm}$ from the reaction of $\operatorname{In}(\mathrm{MA})_{3}$ as an $\mathrm{In}^{3+}$ precursor with either $\mathrm{P}\left(\mathrm{SiMe}_{3}\right)_{3}, \mathrm{HP}\left(\mathrm{SiMe}_{3}\right)_{2}, \mathrm{H}_{2} \mathrm{P}\left(\mathrm{SiMe}_{3}\right)$, or $\mathrm{P}\left(\mathrm{SiPh}_{3}\right)_{3}$ as a $\mathrm{P}^{3-}$ precursor (Figure 1a, $\mathrm{S}_{1}, \mathrm{~S}_{2}, \mathrm{~S}_{3}$, and $\left.\mathrm{S}_{4}\right) .{ }^{12,16}$ The final spectrum is indicative of at least two distinct cluster sizes as there is shoulder present at $420 \mathrm{~nm}$ just before the LEET. This collection of clusters appears to be kinetically persistent below $120{ }^{\circ} \mathrm{C}$ for at least $24 \mathrm{~h}$ in hydrocarbon solvent and have thus been hypothesized to be MSCs (Scheme $1 \mathrm{~A}$, Figure $\mathrm{S}_{1}$ and $\mathrm{S}_{2}$ ). Once isolated from solution, the MSCs can be stored as a solid at room temperature under nitrogen indefinitely. At temperatures of $150{ }^{\circ} \mathrm{C}$ and higher, the MSCs were observed to undergo heterogeneous growth directly to InP QDs without the observation of intermediate-sized particles. The first peak indicating formation of InP QDs exhibits a LEET that corresponds to an initial diameter of about $3 \mathrm{~nm}$. There are no intermediate sizes observed in this reaction from timed aliquots by UV-Vis spectroscopy (Figure $1 b$ ). The spectra of the QDs synthesized in situ via MSCs at modest temperatures $\left(150{ }^{\circ} \mathrm{C}\right)$ red-shifted and broadened over time as the peak from the nanoclusters grew out until only QDs remained over the course of approximately 20 hours (Figure $\mathrm{S}_{2}$ ). The insensitivity of the size and size distribution of the MSCs to the reactivity of the $\mathrm{P}^{3-}$ source as well as the observation of heterogeneous growth from clusters directly to QDs further supports the assignment of these clusters as MSCs.

InP QD syntheses that employ fatty acid ligands and their indium salts typically require elevated growth temperatures $\left(200{ }^{\circ} \mathrm{C}\right.$ or higher) in order to obtain high quality, crystalline particles with narrow size distributions. ${ }^{13,15}$ Xie et al. discovered that incorporating primary amines into these syntheses enabled the formation of high quality samples of InP with LEETs ranging from $390 \mathrm{~nm}$ to 720 $\mathrm{nm}$ at temperatures below $190{ }^{\circ} \mathrm{C}^{15}$ Since this discovery, primary alkyl amines have been utilized as "precursor activating agents" for the preparation of InP QDs at lower temperatures. ${ }^{19,43,44}$

Primary alkyl amines have been assigned multiple roles in the synthesis of InP QDs ranging from ligands, ${ }^{45}$ to a base that modulates the protonolysis of $\mathrm{P}\left(\mathrm{SiMe}_{3}\right)_{3}$ by myristic acid. ${ }^{16}$ Allen et al. were able to demonstrate that primary amines inhibit precursor conversion conflicting with previous claims that amines are precursor activating agents. ${ }^{15,46}$ The direct condensation reaction between carboxylic acids and amines at elevated temperatures (up to $160{ }^{\circ} \mathrm{C}$ ) has been reported to proceed with high yields even in the absence of a catalyst. ${ }^{47}$ The in situ water generated from this reaction has been proposed to hydrolyze the surface bound indium to form an $\operatorname{In}_{2} \mathrm{O}_{3}$ shell, inhibit- ing further growth, further compounding the precise role of primary amines in particle growth. ${ }^{44}$
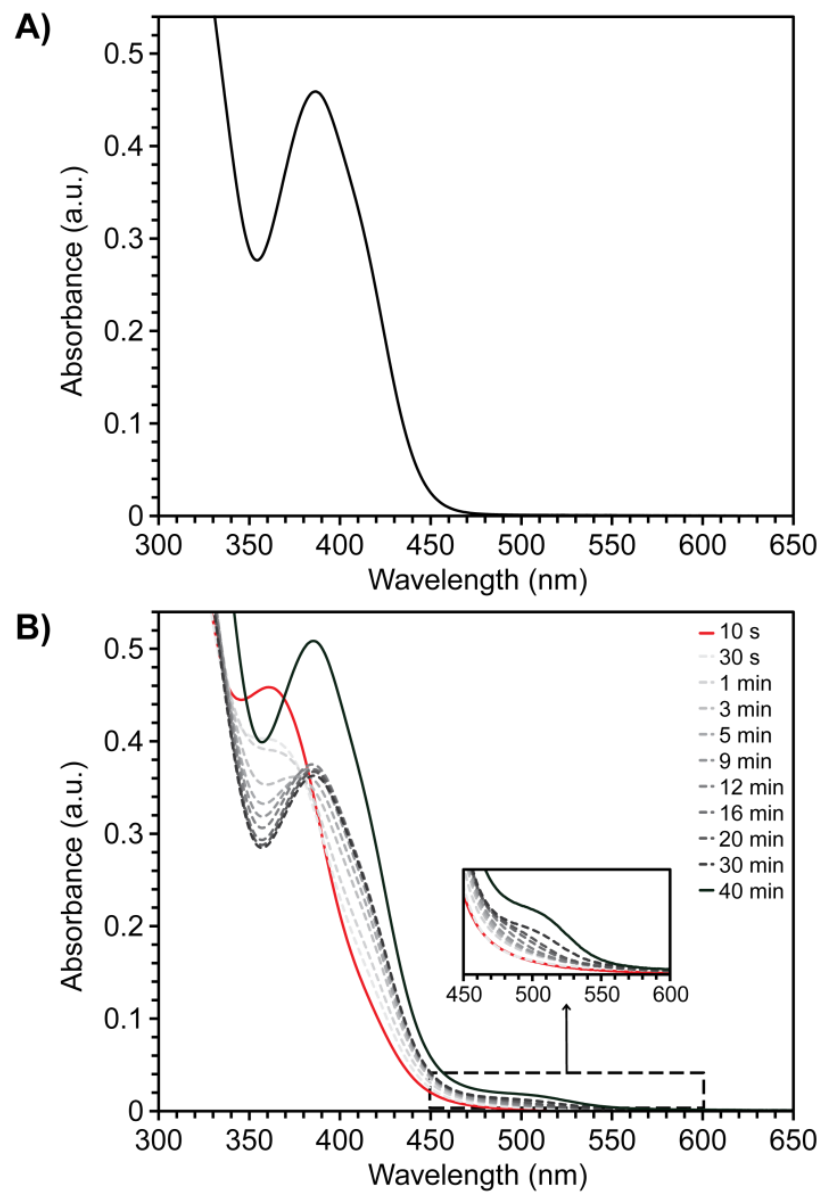

FIGURE 1. A) UV-Vis spectrum of InP MSCs grown in toluene at $110^{\circ} \mathrm{C}$ from $\mathrm{P}\left(\mathrm{SiMe}_{3}\right)_{3}$ and $\operatorname{In}(\mathrm{MA})_{3}$. B) UV-Vis spectra of timed aliquots depicting the formation of InP MSCs in 1octadecene followed by heterogeneous growth directly to InP QDs at $150{ }^{\circ} \mathrm{C}$. The inset shows a close-up of the region depicting InP QD growth.

The experimental conditions where we have observed heterogeneous growth of QDs directly from MSCs are analogous to previously reported syntheses of InP QDs at temperatures below $200{ }^{\circ} \mathrm{C}$ with the exception of the primary alkyl amine. We have performed experiments in order to assess the effect of octylamine (OAm) on the formation of MSCs and their subsequent conversion to QDs. In contrast to experiments where amine is excluded (Figure $1 \mathrm{~B}$ ), we observe homogenous growth of ultrasmall nanoparticles at $160{ }^{\circ} \mathrm{C}$ with LEETs ranging from 415 $\mathrm{nm}$ to $455 \mathrm{~nm}$ when OAm is included in the injection syringe without the appearance of the MSCs at $386 \mathrm{~nm}$ (Scheme 1B). A separate QD population was not observed when the primary amine was present even after 48 hours of growth at $160{ }^{\circ} \mathrm{C}$ (Figure 2a). A subsequent heating of this reaction to $300{ }^{\circ} \mathrm{C}$ revealed further homogenous growth until a LEET at $500 \mathrm{~nm}$ was obtained. Finally, OAm was added to the flask where amine was originally excluded from the injection. The remaining MSCs rapidly switched from a heterogeneous growth pathway to a ho- 
mogenous growth pathway in a manner analogous to incorporating amine in the initial injection syringe (Figure 2b). It was detrimental to the final size distribution of QDs to allow the MSCs to fully form as is evident from the comparison of the full width at half maximum of the spectra from Figure $2 a$ and Figure $2 b$.

These results suggest that the main effect of primary amines is to destabilize the MSCs and thereby switch the growth profile of InP QDs from heterogeneous from MSCs, to homogenous from molecular precursors. In this way, amine can still facilitate formation of InP QDs with narrow size distributions at low temperatures despite the inhibition of the precursor conversion event. ${ }^{46}$ This behaviour is similar to that recently reported for $\mathrm{ZnTe}$ MSCs. ${ }^{28}$ In this report, Zhang et al. discovered that ZnTe MSCs would undergo stepwise growth to nanowires in the absence of oleic acid and continuous growth in the presence of oleic acid. The absorption spectra of purified samples of InP MSCs with myristate (MA) ligands were also found to broaden and red shift when exposed to OAm at room temperature in a nitrogen filled glovebox, suggesting that this effect is due to a direct interaction of the amine with the MSCs rather than a side reaction (Figure $\mathrm{S}_{5}$ ).

The effect of amines on the MSCs suggests that surface chemistry plays a critical role on the stability of the InP MSCs. In line with this hypothesis, we set out to replace the carboxylate ligand set of InP MSCs and assess the stability of the resultant MSCs. Phosphonic acids have been identified as more strongly coordinating capping ligands than carboxylic acids for CdSe QDs due to their superior binding strength. ${ }^{48,49}$ We synthesized InP MSCs with a phosphonate ligand set via $\mathrm{P}\left(\mathrm{SiMe}_{3}\right)_{3}, \operatorname{In}\left(\mathrm{O}_{3} \mathrm{P}(\mathrm{CH})_{17} \mathrm{CH}_{3}\right)_{1.5}$ (indium octadecylphosphonate, $\operatorname{In}(\mathrm{ODPA})_{1.5}$ ), and $\mathrm{H}_{2} \mathrm{O}_{3} \mathrm{P}(\mathrm{CH})_{17} \mathrm{CH}_{3}$ (octadecylphosphonic acid) (Scheme ${ }_{1} \mathrm{C}$, Figure $3 \mathrm{a})$. Comparing the UV-Vis absorption spectra of timed aliquots from both the InP MA MSCs and the octadecylphosphonate (ODPA) terminated InP MSCs reveals sharper features (FWHM $18 \mathrm{~nm}$ versus $72 \mathrm{~nm}$ ) for the InP ODPA MSC including three additional high energy electronic transitions beyond the LEET (397 nm) at $355 \mathrm{~nm}$, $285 \mathrm{~nm}$, and $238 \mathrm{~nm}$.

At first glance, these spectra resemble those reported for CdSe nanoplatelets..$^{50,51}$ Simple mathematical calculations were performed to assess if the final spectrum of InP ODPA MSCs could be interpreted through the model of an infinite one-dimensional potential quantum well as has been previously reported for CdSe platelets (see SI)..$^{\circ}$ According to these calculations, such a structure with a LEET of $397 \mathrm{~nm}$ would have higher energy transitions at $146 \mathrm{~nm}, 71.0 \mathrm{~nm}$, and $41.5 \mathrm{~nm}$ respectively instead of those observed at $355 \mathrm{~nm} 285 \mathrm{~nm}$ and 238nm. TEM analysis also rules out the presence of platelets (Figure S6). Furthermore, it is unlikely that the final spectrum is indicative of four separate MSCs since we observe all four absorption peaks growing in over the same time period for several syntheses. One would expect smaller MSCs to precede larger MSCs, especially in a synthesis from molecular precursors. Also, the final spectrum of InP ODPA MSCs per- sists for at least 3 days at $370{ }^{\circ} \mathrm{C}$ (Figure S8) with all transitions still present at the same relative intensities after this time. These observations support the assignment of the final spectra in Figure 3 as a single phosphonate terminated InP MSC with at least 4 distinct transitions rather than four separate absorbers.
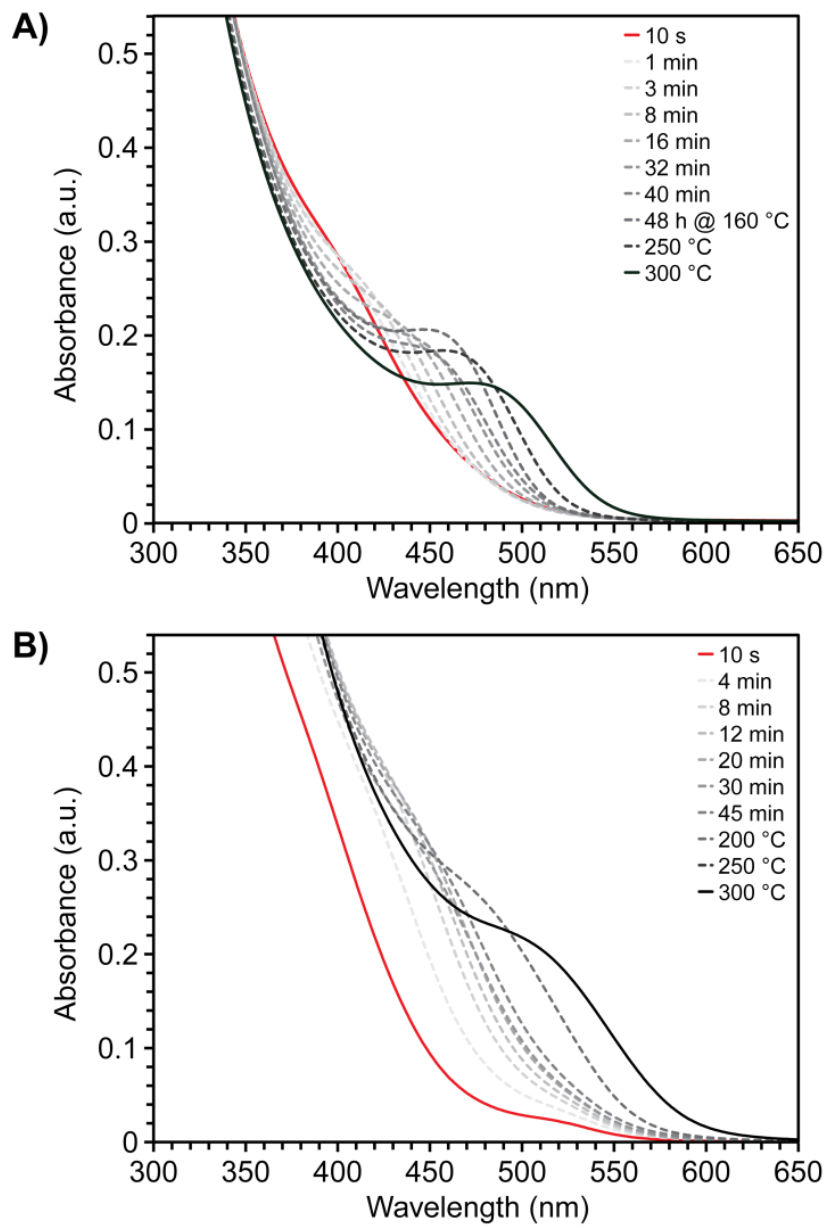

Figure 2. A) UV-Vis spectra of timed aliquots from a hotinjection reaction of $\mathrm{P}\left(\mathrm{SiMe}_{3}\right)_{3}, \mathrm{OAm}$, and $\mathrm{In}(\mathrm{MA})_{3}$ in 1octadecene, where OAm was included in the injection syringe with $\mathrm{P}\left(\mathrm{SiMe}_{3}\right)_{3}$. After 48 hours of growth at $160{ }^{\circ} \mathrm{C}$ the reaction was heated up to $300{ }^{\circ} \mathrm{C}$ with aliquots monitored every $50{ }^{\circ} \mathrm{C}$. B) UV-Vis spectra of timed aliquots from the addition of OAm to InP MSCs at $160{ }^{\circ} \mathrm{C}$. After 48 hours after OAm injection, the reaction was heated up to $300{ }^{\circ} \mathrm{C}$.

The UV-Vis spectra of the phosphonate clusters are completely unaltered after exposure to air for 24 hours (Figure $\mathrm{S}_{7}$ ) suggesting that the InP ODPA MSC is air stable. In contrast, the peak in the UV-Vis spectrum of purified carboxylate clusters was found to broaden significantly after $20 \mathrm{hr}$ in air (Figure $\mathrm{S}_{7}$ ). As envisioned, the phosphonate ligand set did enhance the thermal stability of the resultant InP MSC. The MSC with a phosphonate ligand set are stable in solution at $370{ }^{\circ} \mathrm{C}$ for at least three days (Figure S8). In contrast to the InP MA MSCs, the UV-Vis spectrum of the InP ODPA MSC persists even upon exposure to primary, secondary, or tertiary fatty amines at elevated temperatures $\left(370^{\circ} \mathrm{C}\right.$, Figure S9). 
This observation of the strong dependence of MSC thermal stability on the nature of the ligand set is mirrored by reports in the $\mathrm{CdSe}$ literature. Thermal stability of CdSe MSCs ranges from room temperature nucleants for nanoplatelets (amine terminated), ${ }^{36}$ to quantized growth through families of MSCs at temperatures up to $115{ }^{\circ} \mathrm{C}$ (mixture of carboxylate and amine ligands),,$^{30,34}$ and finally to MSCs that are present at temperatures as high as $300{ }^{\circ} \mathrm{C}$ for $\sim 30$ minutes (phosphonate ligand set)..$^{22}$
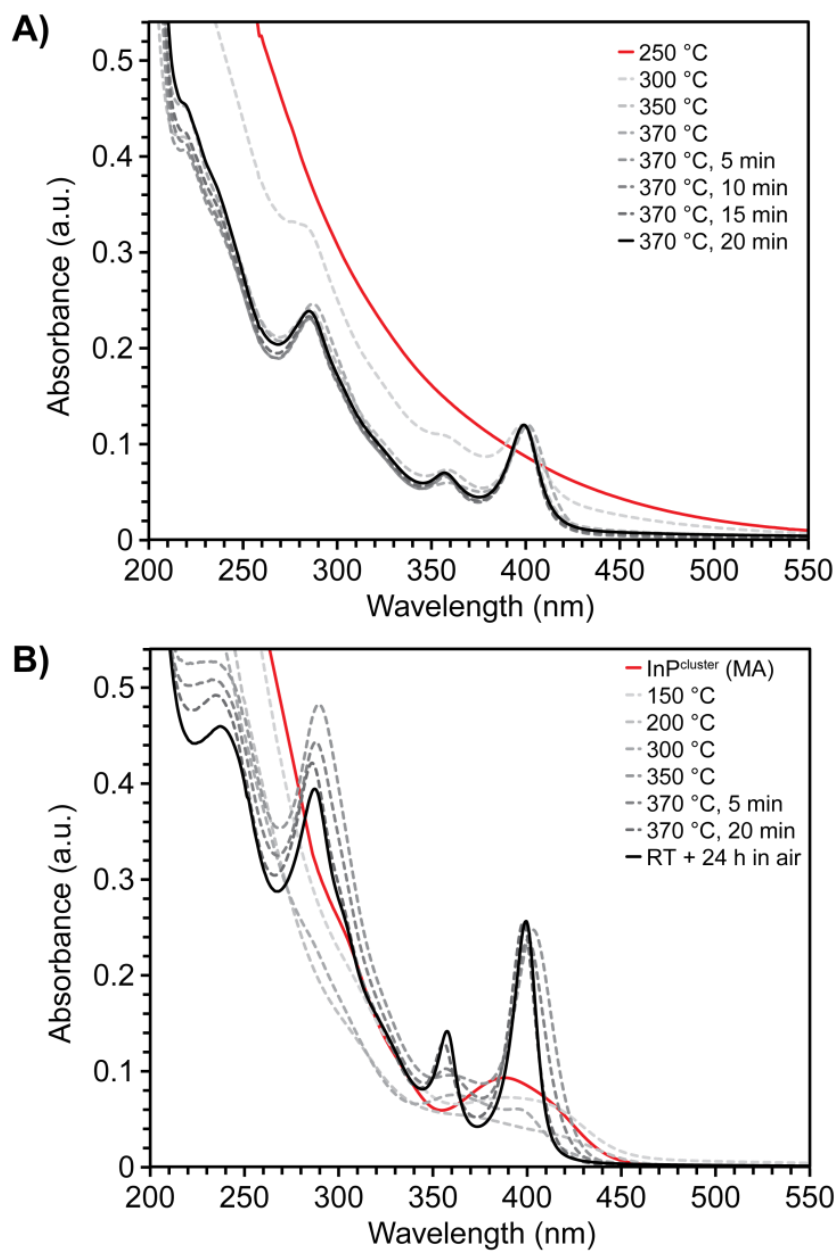

Figure 3. A) InP ODPA MSCs synthesized by injection of $\mathrm{P}\left(\mathrm{SiMe}_{3}\right)_{3}$ into $\operatorname{In}(\mathrm{ODPA})_{1.5}$ at $250^{\circ} \mathrm{C}$ followed by rapid heat up to $370^{\circ} \mathrm{C}$. B) Synthesis of InP ODPA MSCs via injection of InP MA MSCs (red colour trace) into a solution of In(ODPA $)_{1.5}$ at $150{ }^{\circ} \mathrm{C}$ followed by rapid heat up to $370{ }^{\circ} \mathrm{C}$. The black trace is of the final product after cooling to room temperature and exposure to air for $24 \mathrm{~h}$.

The most convincing piece of evidence we observed for the greater stability of the phosphonate MSC relative to the carboxylate MSCs is that the carboxylate MSCs can be used as precursors for the phosphonate MSC. If isolated carboxylate MSCs are injected into In(ODPA) $)_{1.5}$ and heated up to $370{ }^{\circ} \mathrm{C}$ we observe similar, yet sharper (LEET FWHM = 12) features in the UV-Vis to the synthesis that employed $\mathrm{P}\left(\mathrm{SiMe}_{3}\right)_{3}$ (Scheme $\mathrm{1D}$, Figure $\left.3 \mathrm{~b}\right)$. We have synthesized the InP ODPA MSC via oleic acid terminated MSCs in order to assess whether carboxylate ligands are retained in this reaction. ${ }^{1} \mathrm{H}$ NMR of purified InP MSCs reveal a phosphonate to carboxylate ratio of about 44: 1 demonstrating nearly full conversion to a phosphonate ligand set. (Figure S1o) It is interesting to note that the LEET we observe for the phosphonate cluster is within $0.032 \mathrm{eV}$ of the HOMO-LUMO gap from DFT calculations of a an InP cluster $\left([\mathrm{InP}]_{65}\right.$, diameter $\left.=1.86 \mathrm{~nm}\right)$ predicted to be a magic-size for InP. ${ }^{17}$ This is the only prediction of a magic-size for InP to the best of our knowledge.

InP QDs synthesized with MA ligands do not yield InP ODPA MSCs even when exposed to In(ODPA) $)_{1.5}$ at elevated temperatures $\left(370^{\circ} \mathrm{C}\right)$ for four days (Figure S11). These results suggest that the relative stability is as follows: carboxylate terminated InP MSCs < phosphonate terminated InP MSC < InP QDs.

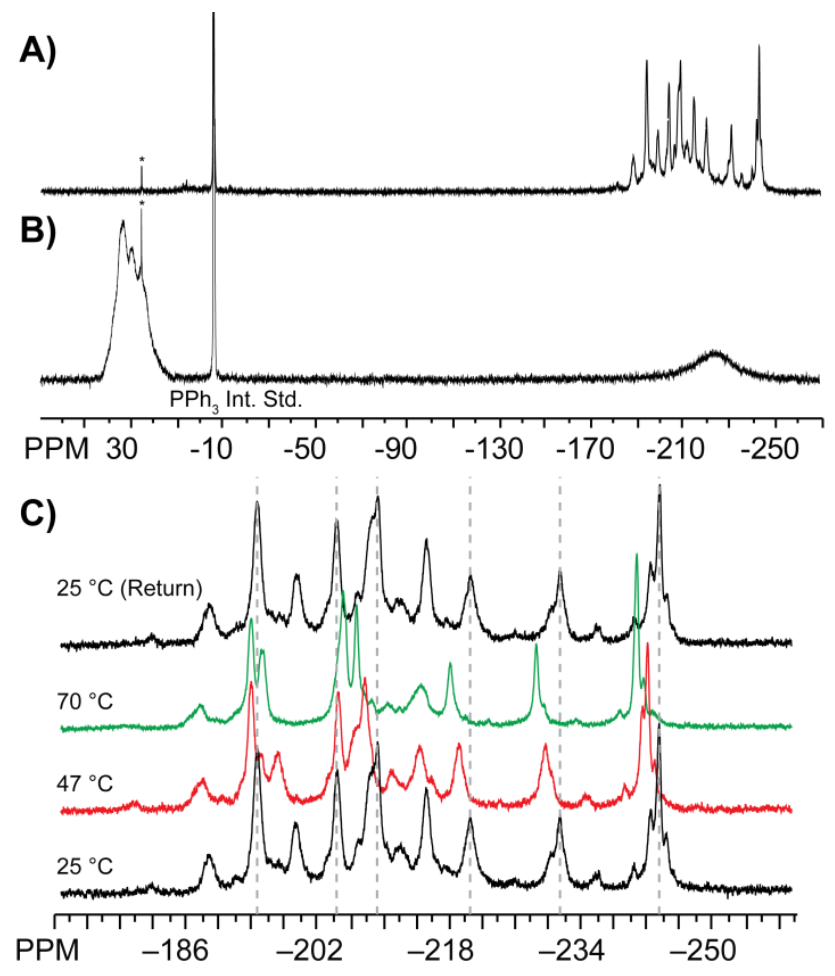

Figure 4. A) ${ }^{31} \mathrm{P}\left\{{ }^{1} \mathrm{H}\right\}$ NMR spectrum of InP MA MSCs acquired at $202.4 \mathrm{MHz}$ in $\mathrm{C}_{6} \mathrm{D}_{6}$. B) ${ }^{31} \mathrm{P}\left\{{ }^{1} \mathrm{H}\right\}$ NMR spectrum of the InP ODPA MSC acquired at 202.4 MHz in $\mathrm{C}_{6} \mathrm{D}_{6}$. C) Variable temperature ${ }^{31} \mathrm{P}\left\{{ }^{1} \mathrm{H}\right\}$ NMR spectra of the InP MA MSCs acquired at $202.4 \mathrm{MHz}$ in $\mathrm{C}_{6} \mathrm{D}_{6}$ collected at $25{ }^{\circ} \mathrm{C}, 47^{\circ} \mathrm{C}, 70^{\circ} \mathrm{C}$, and at $25{ }^{\circ} \mathrm{C}$ after the sample was heated to $70{ }^{\circ} \mathrm{C}$. Dotted lines serve as a guide to the eye for five peaks that shift downfield when heated and return upon cooling to $25^{\circ} \mathrm{C}$.

${ }^{31} \mathrm{P}\left\{{ }^{1} \mathrm{H}\right\}$ NMR spectroscopy was used to further characterize InP MSCs with both kinds of ligand sets (Figure 4 ). In the spectrum of the MSC with the phosphonate ligand set we observe three distinct peaks at 34, 30, and 26 ppm which we assign to ${ }^{31} \mathrm{P}$ environments in the phosphonate ligand set because their chemical shifts are similar to those seen for bound phosphonate ligands on CdSe QDs. ${ }^{49}$ We also observe a broader peak at -224 ppm that we assign to ${ }^{31} \mathrm{P}$-In environments in the MSC based upon ${ }^{31} \mathrm{P}\left\{{ }^{1} \mathrm{H}\right\}$ MAS NMR spectra of powder samples of InP QDs ${ }^{14}$. 
In contrast, the ${ }^{31} \mathrm{P}\left\{{ }^{1} \mathrm{H}\right\}$ NMR spectrum of the InP MSCs with the carboxylate ligand set exhibit at least 19 distinct peaks ranging from -181 to $-243 \mathrm{ppm}$. While this result was unexpected, this spectrum is reproducible from batch to batch. Variable temperature (VT) ${ }^{31} \mathrm{P}\left\{{ }^{1} \mathrm{H}\right\}$ NMR spectra for the myristate terminated cluster reveal that the ${ }^{31} \mathrm{P}$ environments in this material are temperature dependent and the presumed structural changes are fully reversible between $25^{\circ} \mathrm{C}$ and $70{ }^{\circ} \mathrm{C}$ (Figure $4 \mathrm{C}$ ).

Further evidence for the structural differences between the carboxylate and phosphonate-capped MSCs is seen in the powder X-ray diffraction (XRD) (Figure S12) pattern and the atomic pair distribution function (PDF) analysis (Figure 5). The XRD pattern for MSCs of both ligand sets are similar to those reported for powder samples of InP QDs, but with considerable peak broadening as would be expected from a small particle size. The carboxylate terminated clusters exhibit a broad peak at $20^{\circ} 2 \Theta$ that is not present for the phosphonate cluster or for either QD sample, possibly suggestive of amorphous material. The position of the (220) plane for the carboxylate terminated cluster is also significantly shifted from the values for bulk InP while the phosphonate terminated cluster shows no appreciable shift. The PDF analysis of clusters with each ligand set demonstrate that while both clusters are of a similar size $(1-2 \mathrm{~nm})$, intra-molecular atomic distances reveal very different internal structures (Figure 5).

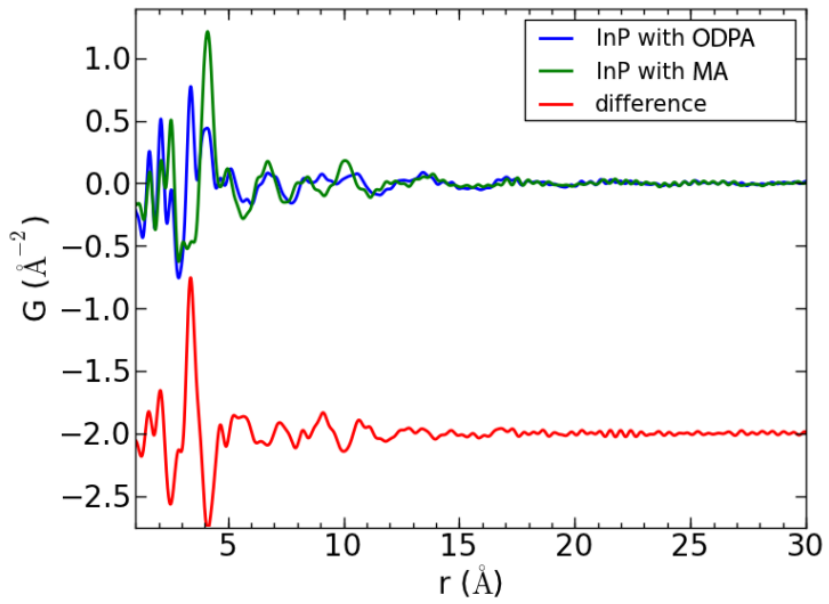

Figure 5. PDF analysis of InP MSCs with ODPA (blue) or MA ligands (green), and their difference (red). Sharp correlations indicate intra-cluster distances up to $\sim 12 \AA$. There is some suggestion that intra-molecular correlations survive to $15^{-17}$ $\AA$ in the MA capped particles, most clearly evident in the difference curve. Broad particle-to-particle correlations can be observed in the high-r region indicative of particle diameters of approximately 1-2 $\mathrm{nm}$. The difference between the two radial distribution functions obtained suggests that while particle size is similar, the core structure of the MSC is dependent on the ligand set.

Taking into consideration the significant change in particle size during heterogeneous growth of InP MSCs to QDs, as well as the thermal stability of InP MSCs, we propose a two-step nucleation model for the formation of InP
QDs from silylphosphines and indium carboxylate precursors (Figure 6). This model was inspired by similar multi-step nucleation schemes proposed for $\mathrm{CaCO}_{3}$ and $\mathrm{Ca}_{3} \mathrm{P}_{2}$ wherein crystallization proceeds through aggregation of stable pre-nucleation clusters..$^{53^{-59}}$ In this model, the MSC is a stable intermediate species that either dissolves back into solution to restore InP monomers which accumulate until a second nucleation event yields InP QDs or MSCs directly aggregate to give InP QDs. Envisioning nucleation of InP via a two-step nucleation scheme has an advantage over classical nucleation theory in that it emphasizes the importance of thermal stability of MSCs on the nucleation and growth of QDs instead of focusing on the precursor conversion event to explain nucleation and growth trends. According to a two-step model, a synthesis targeting a narrow size distribution of QDs from a single hot injection with molecular precursors should aim to minimize the lifetime of the MSCs in order to reduce disparity in particle growth history. This is in agreement with the observation that syntheses for high quality InP QDs employ either elevated temperatures or primary amines.

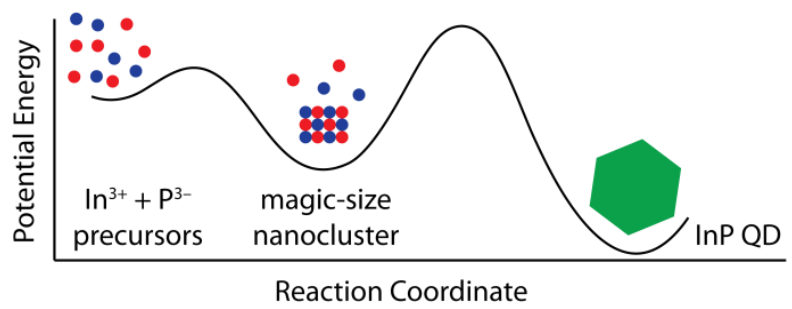

Figure 6. Illustration of the two-step nucleation mechanism for the growth of InP QDs from $\operatorname{In}^{3+}$ and $\mathrm{P}^{3^{-}}$precursors depicting the MSC as an isolable intermediate species that acts as a bottleneck for InP monomers. Amines destabilize the MSC (increase potential energy) while a phosphonate ligand set increases the stability of the MSC relative to a carboxylate ligand set.

Previous studies have demonstrated that inorganic clusters of CdSe can be employed as SSPs for crystalline CdSe QDs with narrow size distributions. ${ }^{60} \mathrm{CdSe}$ and copper organometallic clusters have been used in tandem as a means to synthesize precision doped CdSe:Cu QDs. ${ }^{56}$ Inspired by these syntheses, we explored the utility of InP MSCs as SSPs to InP QDs. InP MSCs with a carboxylate ligand set were chosen to carry out these studies instead of the MSC with a phosphonate ligand set because the extreme thermal stability of phosphonate capped clusters precludes a second nucleation unless indium myristate is added to the reaction to destabilize the cluster. Additionally, thermal decomposition of indium myristate sets an upper limit on the injection temperature for the synthesis of InP QDs from the InP ODPA MSC to $\sim 320{ }^{\circ} \mathrm{C}$ (Figure $\mathrm{S}_{13}$ ).

Our approach differs from the previous syntheses that employ inorganic molecular complexes as SSPs, ${ }^{60,61}$ in that the MSCs were not designed specifically to serve as an SSP. Rather, it is an intermediate to QDs when employing silylphosphines and indium carboxylates as the mo- 
lecular precursors. Utilizing the MSCs as SSPs effectively decouples the formation of the MSCs from the subsequent secondary nucleation and growth of QDs. The monomers produced solely from InP MA MSCs should be inherently different than the monomers used in the first nucleation event to produce the MSCs since we observe $\mathrm{SiMe}_{3}$ groups are not retained for purified InP MA MSCs by ${ }^{1} \mathrm{H}$ NMR (Figure S14)

Purified MSCs were directly substituted for molecular precursors in a hot-injection synthesis. This technique did indeed yield high quality InP QDs within 1 min of injection of MSCs into squalane at $400{ }^{\circ} \mathrm{C}$ (Scheme $1 \mathrm{E}$, Figure 7a). Additionally, XRD of QDs synthesized from MA MSCs as SSPs confirm that the particles produced are highly crystalline despite a growth time of only one minute (Figure S12). Employing purified MSCs as SSPs effectively decouples the precursor conversion event from the second nucleation event. This eliminates the role of precursor conversion in the rate of InP monomer generation for the and nucleation event, thereby simplifying the overall reaction scheme and improving the reproducibility of the synthesis. Additional free ligands should not be necessary in this synthesis as the total amount of indium and phosphorus will remain constant throughout the synthesis while the total surface area to volume ratio will decrease from the conversion of MSCs to QDs.

In order to assess the effect of concentration on these syntheses, the total amount of MSCs injected was varied while holding all other parameters constant (Figure $7 \mathrm{~b}$ ). UV-Vis spectra of 1 min timed aliquots from each of these syntheses followed the expectations of classical nucleation theory across a large range of concentrations. First, at higher concentrations $(12-400 \mathrm{mg}$ of MSCs in $3.5 \mathrm{~mL}$ of squalane) we observed that an increase in concentration of MSCs corresponded to an increase in the final QD size. Second, for low concentrations of MSCs (3- $6 \mathrm{mg}$ of MSCs in $3.5 \mathrm{~mL}$ of squalane) we observe a reversal of the trend seen at higher concentrations. UV-Vis spectra of 1 min timed aliquots exhibit a red shift and broadening of the LEET as concentration decreases in a lowconcentration regime. This threshold concentration for distinct nucleation and growth is readily explained from inferring a LaMer mechanism. ${ }^{62}$ In a high concentration regime, a larger portion of InP monomers remain after the nucleation event for further growth while at lower concentrations nucleation and growth are not temporally distinct due to relatively low InP monomer concentrations. Beyond a given threshold, lower InP monomer concentrations result in a greater portion of the monomers produced being consumed for growth rather than for nucleation. This results in a larger final particle size.

These trends suggest that the conversion of InP MSCs to QDs proceeds via a supersaturated solution rather than direct aggregation of MSCs in line with a two-step nucleation model. Additionally, transmission electron microscopy (TEM) images of InP QDs synthesized by this method show a uniform, spherical shape (Figure 7c). If growth proceeded through a purely aggregative mechanism, particle shape should show a significant deviation from spherical and particle size distributions should not drastically broaden below a given concentration.
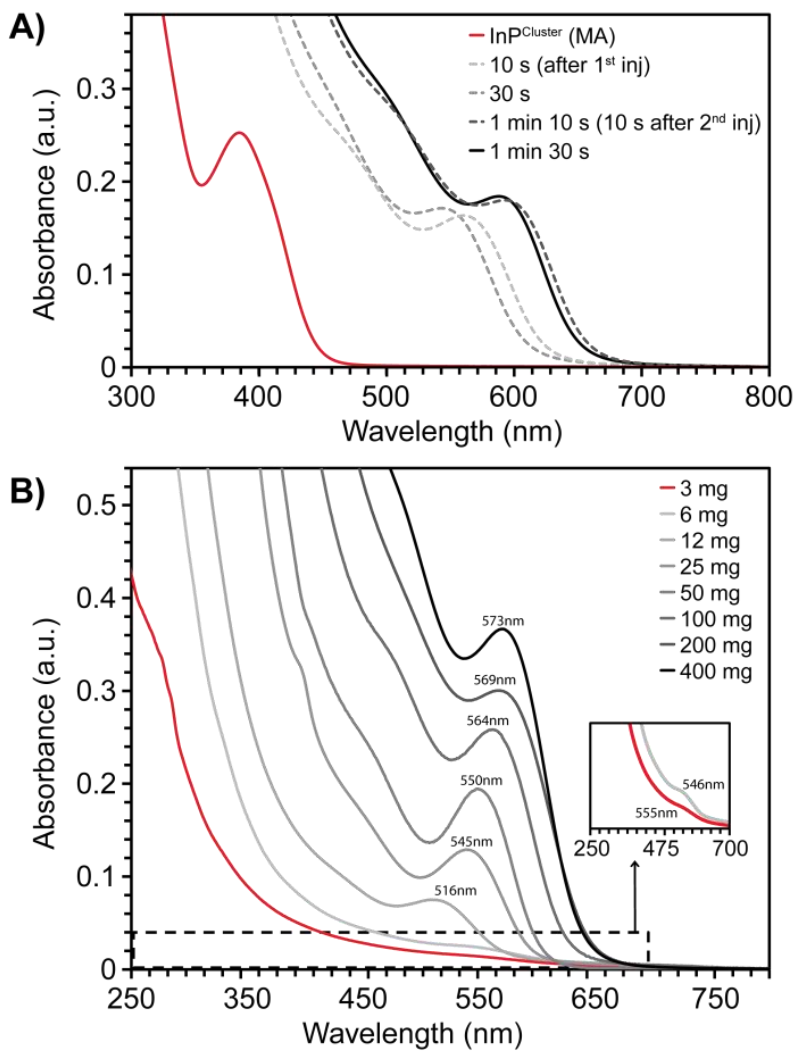

C)

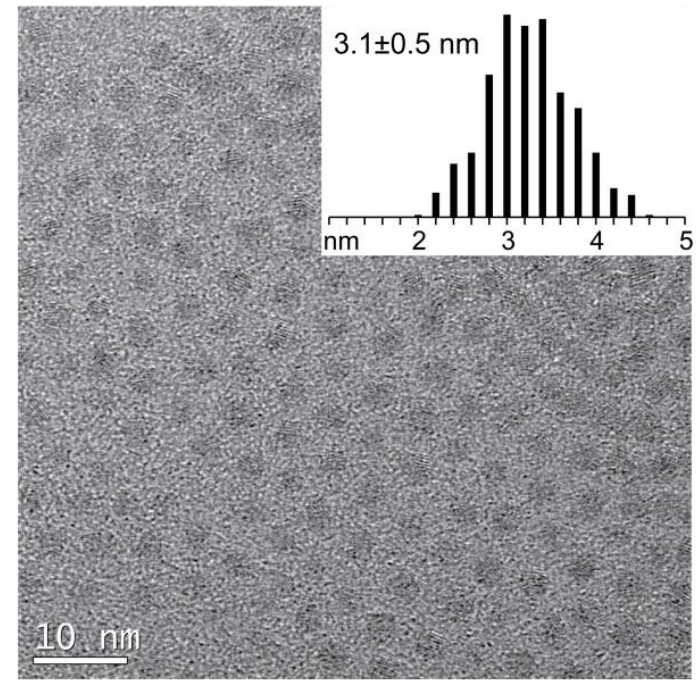

FIGURE 7. A) UV-Vis spectra of timed aliquots from the hotinjection of MSCs into squalane. B) UV-Vis of 1 minute timed aliquots of InP QDs grown using MSCs as SSPs with varying concentration of MSCs employed (squalane volume held at $3.5 \mathrm{~mL}$ ). The synthesis that yielded the narrowest size distribution, as depicted in (C), employed $50 \mathrm{mg}$ of MSCs (3.1 \pm 0.5 $\mathrm{nm}$ ). C) TEM image of InP QDs synthesized from MSCs as SSPs using $50 \mathrm{mg}$ of MSCs and $3.5 \mathrm{~mL}$ of squalane.

\section{CONCLUSIONS}


We have observed that the growth of InP QDs synthesized from indium carboxylates and silylphosphines proceeds via formation of MSCs followed by subsequent heterogeneous growth from the MSCs directly to QDs. We have proposed a two-step nucleation model to account for these observations where the MSCs are kinetically persistent, isolable intermediates. The two nucleation events can be decoupled by means of utilizing isolated MSCs as SSPs. This simple approach has afforded high quality InP QDs without any free ligand, additives, or additional $\mathrm{In}^{3+}$ or $\mathrm{P}^{3^{-}}$sources. By varying the concentration of MSCs employed as SSPs, two trends in final particle size were observed. These two trends can readily be explained from the perspective of a LaMer mechanism of nucleation and growth. This suggests that the second nucleation event proceeds via precipitation from a supersaturated solution of monomers created from dissolution of MSCs rather than an aggregative mechanism directly from MSCs.

Addition of primary amine modulates the growth from a heterogeneous pathway to a homogenous pathway. Primary amines can interact directly with the MSCs, as can be seen from UV-Vis spectra of purified samples prepared under nitrogen. In contrast, the stability of the MSCs is drastically increased by substitution of the carboxylate ligand set for a phosphonate ligand set. The optical properties as well as the structure of the MSC is significantly altered after this conversion as seen from UVVis and ${ }^{31} \mathrm{P}\left\{{ }^{1} \mathrm{H}\right\}$ NMR spectroscopy, as well as XRD and PDF analysis.

These results demonstrate that although MSCs are not predicted by classical nucleation theory they are an important intermediate species in the growth of InP QDs. The two-step nucleation model proposed in this study may help to explain observations for other materials which also have shown heterogeneous growth from MSCs directly to QDs such as $\mathrm{Cd}_{3} \mathrm{P}_{2}{ }^{35}$ The choice of ligand set and additives has a dramatic effect on the stability, structure, and optical properties of such MSCs. Future studies will focus on characterization of InP MSCs with an emphasis on solution ${ }^{31} \mathrm{P}\left\{{ }^{1} \mathrm{H}\right\}$ NMR and single-crystal X-ray diffraction. The utility of MSCs as precursors to other kinds of nanomaterials as well as their potential use as luminophores will also be explored.

\section{EXPERIMENTAL}

Indium acetate (99.99\%), myristic acid ( $\geq 99 \%)$, oleic acid ( $\geq 99 \%)$, toluene $(99.5 \%)$, hexanes (98.5\%), and Celite 545 were purchased from Sigma-Aldrich Chemical Co. and used without further purification. Squalane and 1octadecene $(\geq 95 \%)$ were purchased from Sigma-Aldrich Chemical Co., dried by stirring overnight with $\mathrm{CaH}_{2}$, distilled, and stored over $4 \AA$ molecular sieves prior to use. Triphenylphosphine (99\%) was purchased from Acros Organics and used without further purification. $\mathrm{C}_{6} \mathrm{D}_{6}$ and $\mathrm{CDCl}_{3}$ were purchased from Cambridge Isotope Laboratories and were dried similarly. ${ }^{1} \mathrm{H}$ and ${ }^{31} \mathrm{P}$, NMR spectra were recorded on 300 and $500 \mathrm{MHz}$ Bruker Avance spectrometers. UV-vis spectra were recorded on a Cary 5000 spectrophotometer from Agilent. Powder XRD spectra were collected on a Bruker D8 Discover spectrometer with a GADDS 2-D XRD system. TEM images were collected on an FEI Tecnai G2 F2o microscope. TEM analysis was performed using manual analysis with the help of ImageJ. Histogram, average size, and standard deviation of size for InP QDs from InP MA MSC SSPs were obtained by manual analysis of over 550 particles. Fluorescence spectra were acquired on a Horiba FL3-21tau fluorescence spectrometer. $\mathrm{P}\left(\mathrm{SiMe}_{3}\right)_{3}$ and ODPA were prepared according to literature procedures. ${ }^{16,63-66}$

Preparation of $\operatorname{In}(\mathrm{MA})_{3}$ solution: In a typical synthesis, $0.93 \mathrm{~g}(3.20 \mathrm{mmol})$ of indium acetate and $2.65 \mathrm{~g}$ (11.6 $\mathrm{mmol}$ ) of myristic acid were weighed out into a $100 \mathrm{~mL}$, 14/20, three-neck round-bottom flask equipped with a thermowell, reflux condenser, and septum. The apparatus was evacuated with stirring and raised in temperature to $100{ }^{\circ} \mathrm{C}$. The solution was allowed to off-gas acetic acid under reduced pressure for approximately $12 \mathrm{~h}$ at $100{ }^{\circ} \mathrm{C}$ to generate the $\operatorname{In}(\mathrm{MA})_{3}$ solution. Afterwards, the flask was filled with nitrogen, and a $20 \mathrm{~mL}$ portion of dry toluene was added.

Synthesis of InP MA MSCs from In(MA) ${ }_{3}$ solution and $\mathbf{P}\left(\mathrm{SiMe}_{3}\right)_{3}$ : In a nitrogen filled glovebox, $465 \mu \mathrm{L}$ of $\mathrm{P}\left(\mathrm{SiMe}_{3}\right)_{3}$ was added to $10 \mathrm{~mL}$ of toluene, drawn into a syringe and sealed with a rubber stopper. The In(MA) flask was brought up to $110{ }^{\circ} \mathrm{C}$ and the $\mathrm{P}\left(\mathrm{SiMe}_{3}\right)_{3}$ solution was injected. The formation of MSCs was monitored via UV-Vis of timed aliquots taken from the reaction solution until the MSCs had fully formed as indicated by no further changes in the UV-Vis spectra. This procedure can be easily adapted for a wide variety of fatty carboxylic acids in place of myristic acid.

Synthesis of InP ODPA MSCs from In(ODPA) 1.5 $_{\text {solu- }}$ tion and $\mathrm{P}\left(\mathrm{SiMe}_{3}\right)_{3}$ : In a typical synthesis, $0.117 \mathrm{~g}$ (o.40 $\mathrm{mmol}$ ) of indium acetate and $0.242 \mathrm{~g}(0.725 \mathrm{mmol})$, of octadecylphosphonic acid were weighed out into a $25 \mathrm{~mL}$ 14/20 3-neck round-bottom flask equipped with a stir bar, thermowell, reflux condenser, and septum. Dry squalene ( $5 \mathrm{~mL}$ ) was quickly injected into the 3 -neck flask.

The apparatus was evacuated and raised in temperature to $120{ }^{\circ} \mathrm{C}$. The solution was allowed to off-gas acetic acid under reduced pressure to generate the indium octadecylphosphonate solution for approximately $12 \mathrm{~h}$ at $120{ }^{\circ} \mathrm{C}$.

In the glovebox, a solution of $58 \mu \mathrm{L}(0.20 \mathrm{mmol})$ of $\mathrm{P}\left(\mathrm{SiMe}_{3}\right)_{3}$ in $2.5 \mathrm{~mL}$ of squalane was prepared and drawn up into a plastic syringe stoppered. The 3-neck flask was then filled with nitrogen and rapidly heated by setting the temperature controller to the maximum setting $\left(45^{\circ}{ }^{\circ} \mathrm{C}\right)$. The $\mathrm{P}\left(\mathrm{SiMe}_{3}\right)_{3}$ solution was injected into the indium octadecylphosphonate solution when the temperature controller read $250{ }^{\circ} \mathrm{C}$ as the temperature of the solution was rising. Aliquots were taken during the reaction taking note of the time after injection and the temperature of the flask. Once the reaction solution reached a temperature of $350{ }^{\circ} \mathrm{C}$, the temperature controller was set to $370{ }^{\circ} \mathrm{C}$ for further growth. If the $\mathrm{P}\left(\mathrm{SiMe}_{3}\right)_{3}$ solution is injected at a temperature too far below or above $250^{\circ} \mathrm{C}$, then the MSC 
will not form. The temperature does not need to be this high or well controlled during injection if employing InP MA MSCs instead of $\mathrm{P}\left(\mathrm{SiMe}_{3}\right)_{3}$ as described below.

Synthesis of InP ODPA MSCs from In(ODPA) ${ }_{1.5}$ solution and InP MA MSCs: The synthesis of the InP ODPA MSC from an In(ODPA) $)_{1.5}$ solution and InP MA MSCs follows the same procedure as that for using $\mathrm{P}\left(\mathrm{SiMe}_{3}\right)_{3}$ with a few exceptions:

1.) Substitute $0.200 \mathrm{~g}$ of purified InP MA MSCs for the 58 $\mu \mathrm{L}$ of $\mathrm{P}\left(\mathrm{SiMe}_{3}\right)_{3}$ for the injection solution.

2.) After the $12 \mathrm{hr}$ degassing step for the In(ODPA) $)_{1.5}$ solution, fill the flask with nitrogen, bring the temperature to $300{ }^{\circ} \mathrm{C}$ for a couple of minutes to form a clear, homogenous solution, and finally bring the solution back to $120{ }^{\circ} \mathrm{C}$ and evacuate for another 2 hr degassing step.

3.) Inject the InP MA MSC solution at $100{ }^{\circ} \mathrm{C}$ instead of at $250{ }^{\circ} \mathrm{C}$ to ensure the InP MA MSCs are fully dissolved before reaction with the $\operatorname{In}(\mathrm{ODPA})_{1.5}$ solution to form the InP ODPA MSCs.

InP MA MSCs workup procedure: After UV-Vis confirmed formation of MSCs, the flask was cooled and then carefully evacuated until all of the toluene was removed. The flask was transferred into a nitrogen filled glovebox. The crude MSCs were re-suspended in toluene. The toluene solution was centrifuged to remove insoluble materials. The now transparent supernatant was transferred to a second centrifuge tube. Acetonitrile was added to the solution to precipitate the clusters. The suspension was centrifuged. The supernatant was decanted and discarded and the MSCs were redissolved in a minimal amount of toluene. Again acetonitrile was added, and the suspension was centrifuged. This was repeated for a total of four cycles of precipitation. The MSCs were finally dissolved in 5 $\mathrm{mL}$ of pentane and transferred to a scintillation vial. The scintillation vial was carefully evacuated in the glovebox until a yellow solid was obtained. ${ }^{1} \mathrm{H}$ NMR of this sample shows only bound myristate as evidenced by the broadened and shifted resonances (Figure S14). The purified MSCs did not display any differences in the UV-vis spectrum (no broadening or red shift) when compared with those of the final timed aliquots. These particles are virtually nonfluorescent as isolated (PLQY <1\%).

InP ODPA MSC workup procedure: The workup procedure for InP ODPA MSCs is the same for MSCs synthesized from $\mathrm{P}\left(\mathrm{SiMe}_{3}\right)_{3}$ and for those synthesized with InP MA MSCs. A Schlenk flask was filled with $25 \mathrm{~mL}$ of hexanes, briefly evacuated, and backfilled with nitrogen three times prior to the synthesis of the particles. After UV-Vis confirmed complete conversion to the MSCs, the hot reaction mixture was drawn up into a $10 \mathrm{~mL}$ glass syringe. (Caution! The reaction solution will be incredibly hot (370 ${ }^{\circ} \mathrm{C}$ ) and must be handled with extreme care.) The solution was rapidly injected into hexanes under nitrogen. Rapid cooling with dilution using this strategy was found to be optimal for maintaining the cluster's narrow spectroscopic features. Skipping this step and allowing the reaction flask to come to room temperature results in spectral red- shift and broadening, suggesting aggregation. The flask can be reheated to $370^{\circ} \mathrm{C}$ and rapidly cooled by injecting into room temperature hexanes under nitrogen as previously described to restore the FWHM originally observed from timed aliquots. Following this rapid cooling and dilution, the hexanes were removed under reduced pressure and then the squalene was distilled off under vacuum at a temperature of $200{ }^{\circ} \mathrm{C}$.

After the distillation, the crude MSCs were suspended in toluene by adding toluene to the flask and heating the solution to $100{ }^{\circ} \mathrm{C}$ under nitrogen. After the particles had redissolved, the solution was centrifuged to remove any insoluble materials. The now transparent supernatant was transferred to a second centrifuge tube. Acetonitrile was added to the solution to precipitate the clusters. The suspension was centrifuged. The supernatant was decanted and discarded and the MSCs were redissolved in a minimal amount of toluene. The toluene solution as centrifuged again to remove insoluble materials and the supernatant was transferred to a new centrifuge tube. Three more iterations of alternating precipitations of insoluble material from toluene and MSCs from acetonitrile were conducted to ensure purity. The final particles show no molecular species by ${ }^{1} \mathrm{H}$ NMR (Figure S14). The MSCs were finally dissolved in $5 \mathrm{~mL}$ of pentane and transferred to a scintillation vial. The scintillation vial was carefully evacuated until a yellow solid was obtained. The resulting MSCs did not display any differences in the UV-vis spectrum when compared with those of the final time aliquots. These particles are virtually nonfluorescent as isolated (PLQY $<1 \%$ ).

Synthesis of InP QDs from InP MA MSCs: The desired amount of purified InP MA MSCs were weighed out into a scintillation vial in a glovebox (masses ranged from $3 \mathrm{mg}$ to $400 \mathrm{mg}$ see Figure $7 \mathrm{~b}$ ) and dissolved into $1 \mathrm{~mL}$ of squalene, drawn into a syringe, and stoppered. In a 3-neck flask under nitrogen on a Schlenk line, 2.5 mL of squalane was preheated to $400{ }^{\circ} \mathrm{C}$ using a heating mantle with vigorous stirring. The InP MA MSC solution was rapidly injected into the squalane solution. After one minute of growth, the 3-neck flask was raised out of the heating mantle and lowered into a room temperature silicon oil bath for rapid cooling. (Caution! The reaction solution will be incredibly hot $\left(400{ }^{\circ} \mathrm{C}\right)$ and must be handled with extreme care.) The resulting InP QDs were purified using the same procedure as outlined for InP ODPA MSCs.

UV-Vis monitoring procedure: Prior to each injection $\mathrm{P}\left(\mathrm{SiMe}_{3}\right)_{3}$ or a solution of InP MA MSCs, a test tube rack was prepared with 16 test tubes. Each test tube was filled with $6 \mathrm{~mL}$ of hexanes. $50 \mu \mathrm{L}$ aliquots of the reaction mixture were taken at specific times from injection using a $100 \mu \mathrm{L}$ syringe.

InP MSC J-Young tube sample preparation: $0.3 \mathrm{~g}$ of biphenyl was added to $0.7 \mathrm{~g}$ of diphenyl ether in a scintillation vial and shaken vigorously to obtain a eutectic mixture. This solution was added to $0.1 \mathrm{~g}$ of triphenylphosphine in a separate scintillation vial and thoroughly shaken to fully dissolve the triphenylphosphine. 10 $\mu \mathrm{L}$ of the triphenylphosphine solution was sealed into a 
capillary tube. A supersaturated solution of InP MA MSCs was prepared by dissolving purified MSCs in $\mathrm{C}_{6} \mathrm{D}_{6}$ (40o mg of MSCs in $0.4 \mathrm{~mL}$ of $\mathrm{C}_{6} \mathrm{D}_{6}$ ) and was sealed along with the capillary in a J-Young tube. The J-Young tube solution was sonicated and gently heated $\left(40^{\circ} \mathrm{C}\right)$ prior to collecting data at room temperature to obtain a solution that would remain homogenous for at least $30 \mathrm{~min}$. This action was not required for data collected at elevated temperatures.

Pair distribution function analysis: X-ray total scattering experiments were conducted on beamline $\mathrm{X}_{17} \mathrm{~A}$ at the National Synchrotron Light Source (NSLS) at Brookhaven National Laboratory. An X-ray beam of energy $67.419 \mathrm{keV}$ $(\lambda=0.1839 \AA)$ was focused on samples contained in Kapton capillaries at room temperature. Scattered intensity was collected using the rapid acquisition technique ${ }^{67}$ on a Perkin Elmer 2D flat panel detector (2048 x 2048 pixels and $200 \times 200 \mu \mathrm{m}$ pixel size) mounted orthogonal to the beam path at a distance of $204.9599 \mathrm{~mm}$ from the sample. The experimental setup was calibrated with a Ni standard sample using Fit2D. ${ }^{68}$ The measured 2D intensity was integrated azimuthally to $1 \mathrm{D}$ intensity versus the magnitude of the scattering vector $Q$ using the integration software SrXplanar, ${ }^{69}$ then converted to a real-space pair distribution function (PDF), G(r), by

$$
G(r)=\frac{2}{\pi} \int_{Q_{\min }}^{Q_{\max }} Q[S(Q)-1] \sin (Q r) d Q
$$

using PDFget $\mathrm{X}^{70}$ in PDFgetXgui. ${ }^{71} \mathrm{~S}(\mathrm{Q})$ is the total scattering structure function, and $Q_{\min }$ and $Q_{\max }$ are the minimum and maximum values of the scattering momentum transfer considered.

\section{ASSOCIATED CONTENT}

Supporting Information. Additional experimental details and data are located in the supporting information document accompanying this article. This material is available free of charge via the Internet at http://pubs.acs.org.

\section{AUTHOR INFORMATION}

\section{Corresponding Author}

* cossairt@chem.washington.edu.

\section{Funding Sources}

University of Washington Startup Funds and the University of Washington Royalty Research Fund.

\section{ACKNOWLEDGMENT}

We acknowledge Connor McCue for his work that aided in the synthesis of octadecylphosphonic acid and lead to the discovery of magic-sized InP capped with phosphonate ligands. We gratefully acknowledge the University of Washington Innovation Award and start-up funds for supporting this research. Part of this work was conducted at the University of Washington NanoTech User Facility, a member of the NSF National Nanotechnology Infrastructure Network (NNIN). Use of the National Synchrotron Light Source, Brookhaven National Laboratory, was supported by the U.S. Department of Energy, Office of Science, Office of Basic Energy Sciences, under Contract No. DE-ACo2- 98CH1o886.

\section{ABBREVIATIONS}

QD quantum dot; CdSe, cadmium selenide; InP, indium phosphide; MSC, magic-sized cluster; LEET, lowest energy electronic transition ; In(MA) $)_{3}$ indium myristate; ; SSP, single-source precursor; $\mathrm{ZnS}$, zinc sulfide; OAm, octylamine; MA, myristate; ; In(ODPA $)_{1.5}$, indium octadecylphophonate; ODPA, octadecylphophonate; XRD, X-ray diffraction; PDF, pair distribution function.

\section{REFERENCES}

(1) Wood, V.; Bulović, V. Nano Rev. 2010

(2) Chen, O.; Zhao, J.; Chauhan, V. P.; Cui, J.; Wong, C.; Harris, D. K.; Wei, H.; Han, H.-S.; Fukumura, D.; Jain, R. K.; Bawendi, M. G. Nat. Mater. 2013, 12, 445-451.

(3) Godt, J.; Scheidig, F.; Grosse-Siestrup, C.; Esche, V.; Brandenburg, P.; Reich, A.; Groneberg, D. JOMT 2oo6, 1, 1-6.

(4) Chen, O.; Wei, H.; Maurice, A.; Bawendi, M.; Reiss, P. MRS Bull. 2013, 38, 696-702.

(5) Brunetti, V.; Chibli, H.; Fiammengo, R.; Galeone, A.; Malvindi, M. A.; Vecchio, G.; Cingolani, R.; Nadeau, J. L.; Pompa, P. P. Nanoscale 2013, 5, 307-317.

(6) Chibli, H.; Carlini, L.; Park, S.; Dimitrijevic, N. M.; Nadeau, J. L. Nanoscale 2011, 3, 2552-2559.

(7) Yoffe, A. D. Adv. Phys. 1993, 42, 173-262.

(8) Yang, X.; Zhao, D.; Leck, K. S.; Tan, S. T.; Tang, Y. X.; Zhao, J.; Demir, H. V.; Sun, X. W. Adv. Mater. 2012, 24, 4180-4185.

(9) Cui, J.; Beyler, A. P.; Marshall, L. F.; Chen, O.; Harris, D. K.; Wanger, D. D.; Brokmann, X.; Bawendi, M. G. Nat. Chem. 2013, 5, 602-606.

(10) Harris, D. K.; Bawendi, M. G. J. Am. Chem. Soc. 2012, 134, 20211-20213.

(11) Joung S, Y. S., Han CS, Kim Y, Jeong S. Nanoscale Res. Lett. 2012, 7 .

(12) Gary, D. C.; Glassy, B. A.; Cossairt, B. M. Chem. Mater. 2014, 26, 1734-1744.

(13) Battaglia, D.; Peng, X. Nano Lett. 2002, 2, 1027-1030.

(14) Cros-Gagneux, A.; Delpech, F.; Nayral, C.; Cornejo, A.; Coppel, Y.; Chaudret, B. J. Am. Chem. Soc. 2o10, 132, 18147-18157.

(15) Xie, R.; Battaglia, D.; Peng, X. J. Am. Chem. Soc. 2007, 129, 15432-15433

(16) Gary, D. C.; Cossairt, B. M. Chem. Mater. 2013, 25, 2463-2469.

(17) Cho, E.; Jang, H.; Lee, J.; Jang, E. Nanotechnology 2013 24, 215201.

(18) Rowland, C. E.; Liu, W.; Hannah, D. C.; Chan, M. K. Y.; Talapin, D. V.; Schaller, R. D. ACS Nano 2013, 8, 977-985.

(19) Thomas, A.; Nair, P. V.; George Thomas, K. J Phys. Chem. C 2014, 118, 3838-3845.

(20) Li, L.; Reiss, P. J. Am. Chem. Soc. 2oo8, 130, 11588-11589.

(21) Yin, Y.; Alivisatos, A. P. Nature 2005, 437, 664-670.

(22) Reiss, H. J. Chem. Phys. 1951, 19, 482-487.

(23) McBride, J. R.; Dukes Iii, A. D.; Schreuder, M. A.; Rosenthal, S. J. Chem. Phys. Lett. 2010, 498, 1-9.

(24) Harrell, S. M.; McBride, J. R.; Rosenthal, S. J. Chem Mater. 2013, 25, 1199-1210.

(25) Evans, C. M.; Guo, L.; Peterson, J. J.; MaccagnanoZacher, S.; Krauss, T. D. Nano Lett. 2008, 8, 2896-2899.

(26) Zhang, L.-J.; Shen, X.-C.; Liang, H.; Yao, J.-T. J. Phys. Chem. C 2010, 114, 21921-21927.

(27) Groeneveld, E.; van Berkum, S.; Meijerink, A.; de Mello Donegá, C. Small 2011, 7, 1247-1256.

(28) Zhang, J.; Rowland, C.; Liu, Y.; Xiong, H.; Kwon, S.; Shevchenko, E.; Schaller, R. D.; Prakapenka, V. B.; Tkachev, S.; Rajh, T. J. Am. Chem. Soc. 2014. 
(29) Li, M.; Ouyang, J.; Ratcliffe, C. I.; Pietri, L.; Wu, X.; Leek, D. M.; Moudrakovski, I.; Lin, Q.; Yang, B.; Yu, K. ACS Nano 2009, 3, 3832-3838.

(30) Cossairt, B. M.; Owen, J. S. Chem. Mater. 2011, 23, 31143119.

(31) Dolai, S.; Nimmala, P. R.; Mandal, M.; Muhoberac, B. B.; Dria, K.; Dass, A.; Sardar, R. Chem. Mater. 2013, 26, 1278-1285.

(32) Dukes, A. D.; McBride, J. R.; Rosenthal, S. J. Chem. Mater. 2010, 22, 6402-6408.

(33) Liu, X.; Jiang, Y.; Guo, W.; Lan, X.; Fu, F.; Huang, W.; Li, L. Chem. Eng. J. 2013, 230, 466-474.

(34) Kudera, S.; Zanella, M.; Giannini, C.; Rizzo, A.; Li, Y.; Gigli, G.; Cingolani, R.; Ciccarella, G.; Spahl, W.; Parak, W. J.; Manna, L. Adv. Mater. 2007, 19, 548-552.

(35) Wang, R.; Ratcliffe, C. I.; Wu, X.; Voznyy, O.; Tao, Y.; Yu, K. J. Phys. Chem. C 2009, 113, 17979-17982.

(36) Wang, Y.; Zhang, Y.; Wang, F.; Giblin, D. E.; Hoy, J.; Rohrs, H. W.; Loomis, R. A.; Buhro, W. E. Chem. Mater. 2014, 26, 2233-2243.

(37) Peng, Z. A.; Peng, X. J. Am. Chem. Soc. 20o2, 124, 33433353.

(38) Joo, J.; Son, J. S.; Kwon, S. G.; Yu, J. H.; Hyeon, T. J. Am. Chem. Soc. 2006, 128, 5632-5633.

(39) Son, J. S.; Wen, X.-D.; Joo, J.; Chae, J.; Baek, S.-i.; Park, K.; Kim, J. H.; An, K.; Yu, J. H.; Kwon, S. G.; Choi, S.-H.; Wang, Z.; Kim, Y.-W.; Kuk, Y.; Hoffmann, R.; Hyeon, T. Angew. Chem. Int. Ed. 2009, 48, 6861-6864.

(40) Liu, Y.-H.; Wang, F.; Wang, Y.; Gibbons, P. C.; Buhro, W. E. J. Am. Chem. Soc. 2011, 133, 17005-17013.

(41) Xie, R.; Peng, X. Angew. Chem. Int. Ed. 2oo8, 47, 76777680.

(42) Xie, R.; Li, Z.; Peng, X. J. Am. Chem. Soc. 2009, 131, 15457-15466.

(43) Gao, S.; Zhang, C.; Liu, Y.; Su, H.; Wei, L.; Huang, T.; Dellas, N.; Shang, S.; Mohney, S. E.; Wang, J.; Xu, Opt. Express 2011, 19, 5528-5535.

(44) Protiere, M.; Reiss, P. Chem. Commun. 2007, 2417-2419. (45) Xu, S.; Ziegler, J.; Nann, T. J. Mater. Chem. 2oo8, 18, 2653-2656.

(46) Allen, P. M.; Walker, B. J.; Bawendi, M. G. Angew. Chem. Int. Ed. 2010, 49, 760-762.

(47) Gooßen, L. J.; Ohlmann, D. M.; Lange, P. P. Synthesis 2009, 2009, 160-164.

(48) Gomes, R.; Hassinen, A.; Szczygiel, A.; Zhao, Q.; Vantomme, A.; Martins, J. C.; Hens, Z. J. Phys. Chem. Lett. 2011, 2, 145-152.

(49) Owen, J. S.; Park, J.; Trudeau, P.-E.; Alivisatos, A. P. J. Am. Chem. Soc. 2008, 130, 12279-12281.

(50) Ithurria, S.; Dubertret, B. J. Am. Chem. Soc. 2oo8, 130, 16504-16505.

(51) Ithurria, S.; Tessier, M. D.; Mahler, B.; Lobo, R. P. S. M.; Dubertret, B.; Efros, A. L. Nat. Mater. 2011, 10, 936-941.

(52) Jiang, Z.-J.; Kelley, D. F. ACS Nano 2010, 4, 1561-1572.

(53) Gebauer, D.; Völkel, A.; Cölfen, H. Science 2008, 322, 1819-1822.

(54) Pouget, E. M.; Bomans, P. H. H.; Goos, J. A. C. M.; Frederik, P. M.; de With, G.; Sommerdijk, N. A. J. M. Science 2009, 323, 1455-1458.

(55) Wallace, A. F.; Hedges, L. O.; Fernandez-Martinez, A.; Raiteri, P.; Gale, J. D.; Waychunas, G. A.; Whitelam, S.; Banfield, J. F.; De Yoreo, J. J. Science 2013, 341, 885-889.

(56) Erdemir, D.; Lee, A. Y.; Myerson, A. S. Acc. Chem. Res. 2009, 42, 621-629.

(57) Gebauer, D.; Kellermeier, M.; Gale, J. D.; Bergstrom, L.; Colfen, H. Chem. Soc. Rev. 2014, 43, 2348-2371.

(58) Betts, F.; Posner, A. S. Mater. Res. Bull. 1974, 9, 353-36o.
(59) Betts, F.; Blumenthal, N. C.; Posner, A. S.; Becker, G. L.; Lehninger, A. L. Proc. Natl. Acad. Sci. U. S.A. 1975, 72, 2088-209o.

(6o) Cumberland, S. L.; Hanif, K. M.; Javier, A.; Khitrov, G. A.; Strouse, G. F.; Woessner, S. M.; Yun, C. S. Chem. Mater. 2002, $14,1576-1584$.

(61) Jawaid, A. M.; Chattopadhyay, S.; Wink, D. J.; Page, L. E.; Snee, P. T. ACS Nano 2013, 7, 3190-3197.

(62) LaMer, V. K.; Dinegar, R. H. J. Am. Chem. Soc. 1950, 72, 4847-4854.

(63) Becker, G.; Schmidt, H.; Uhl, G.; Uhl, W.; Regitz, M.; Rösch, W.; Vogelbacher, U.-J. In Inorganic Syntheses; John Wiley \& Sons, Inc.: 2007, p 243-249.

(64) Kosolapoff, G. M. J. Am. Chem. Soc. 1945, 67, 1180-1182.

(65) Zhang, N.; Casida, J. E. J. Org. Chem. 20oo, 66, 327-329. (66) Gaboyard, M.; Hervaud, Y.; Boutevin, B. Phosphorus Sulfur Silicon Relat. Elem. 2002, 177, 877-891.

(67) Chupas, P. J.; Qiu, X.; Hanson, J. C.; Lee, P. L.; Grey, C. P.; Billinge, S. J. L. J. Appl. Crystallogr. 2003, 36, 1342-1347.

(68) Hammersley, A. P.; Svensson, S. O.; Hanfland, M.; Fitch, A. N.; Hausermann, D. High Pressure Res. 1996, 14, 235248.

(69) Yang, X.; Juhas, P.; Billinge, S. J. L. J. Appl. Crystallogr. 2014, 47, 1273-1283.

(70) Juhas, P.; Davis, T.; Farrow, C. L.; Billinge, S. J. L. J. Appl. Crystallogr. 2013, 46, 560-566.

(71) Yang, X., Juhas, P., Farrow, C. L. \& Billinge, S. J. L. PDFgetXgui: a graphical user interface for $\mathrm{PDFget}_{3}$ for high throughput pair distribution function transformation and visualization. ArXiv:1402.3163. V2. 2014. 
Authors are required to submit a graphic entry for the Table of Contents (TOC) that, in conjunction with the manuscript title, should give the reader a representative idea of one of the following: A key structure, reaction, equation, concept, or theorem, etc., that is discussed in the manuscript. Consult the journal's Instructions for Authors for TOC graphic specifications.

Insert Table of Contents artwork here

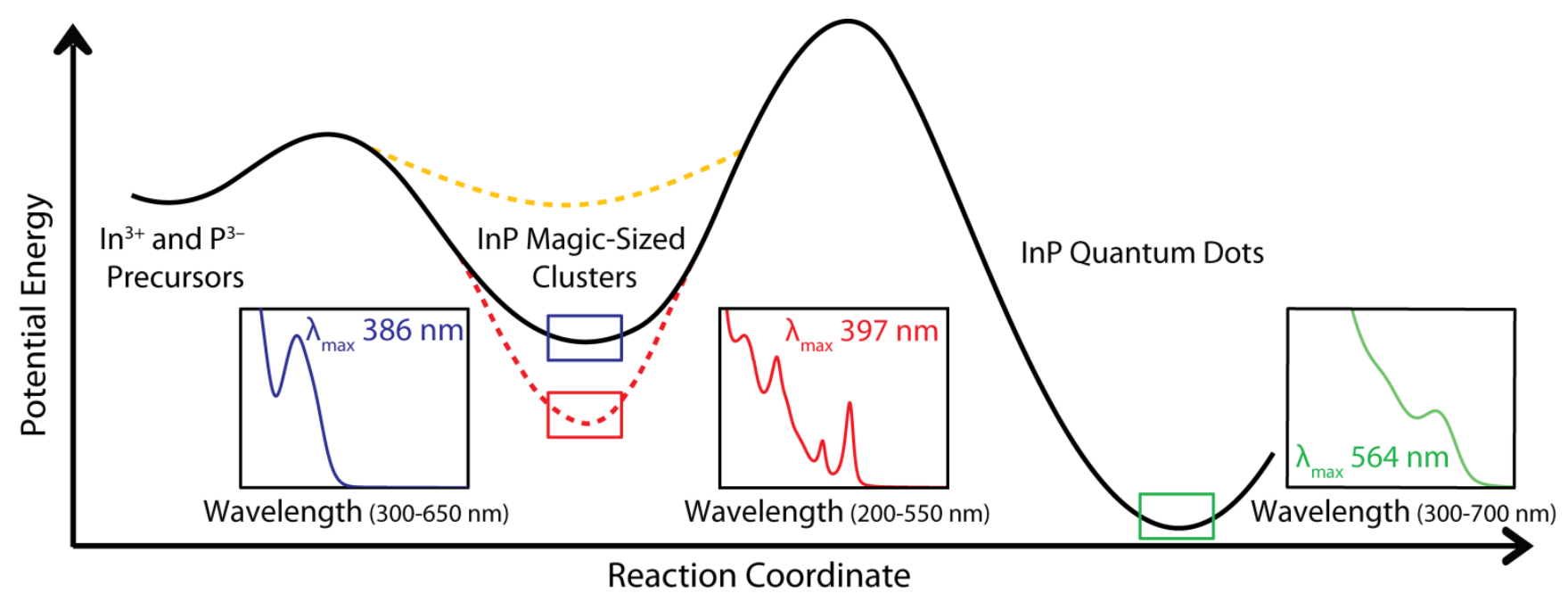




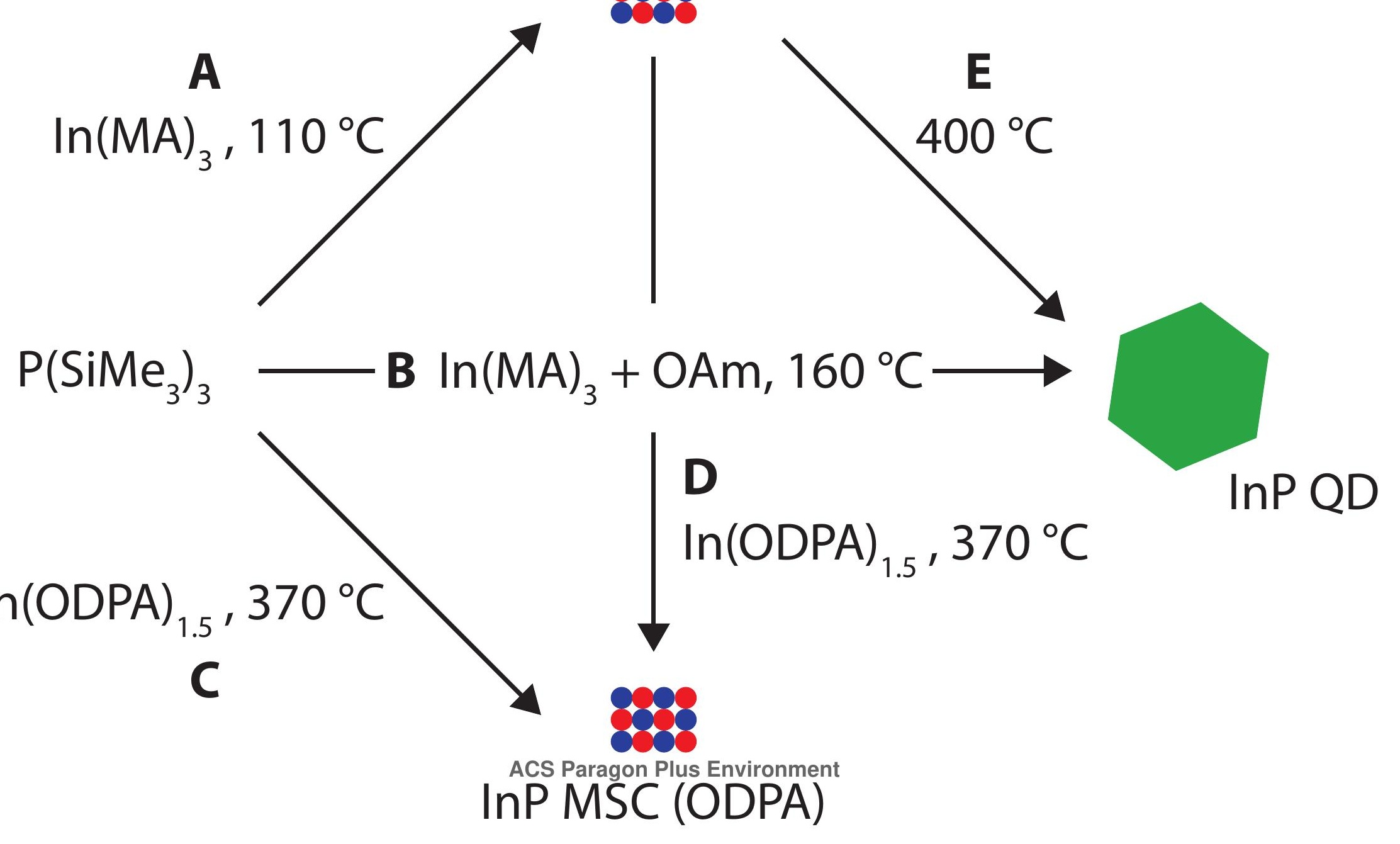



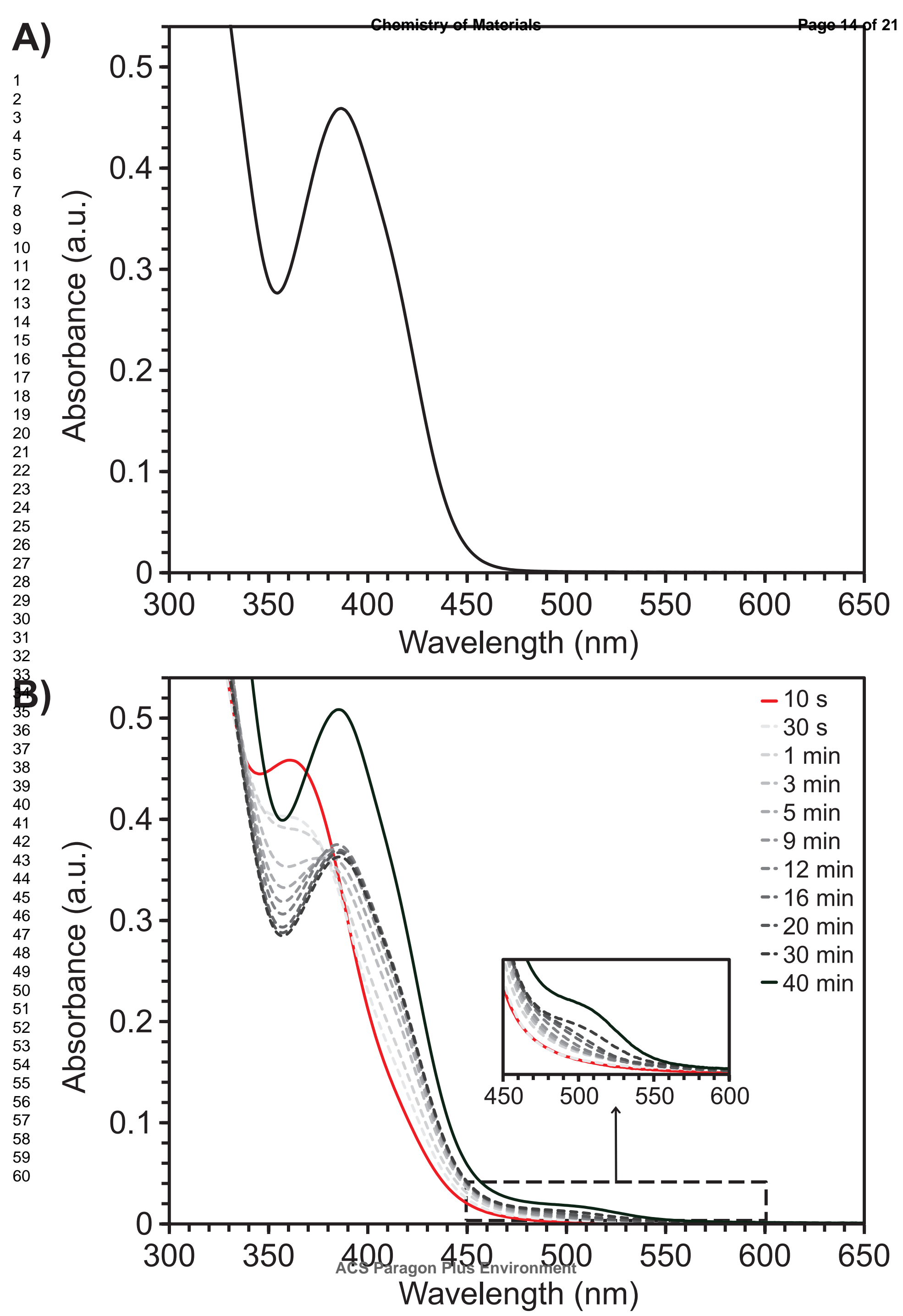

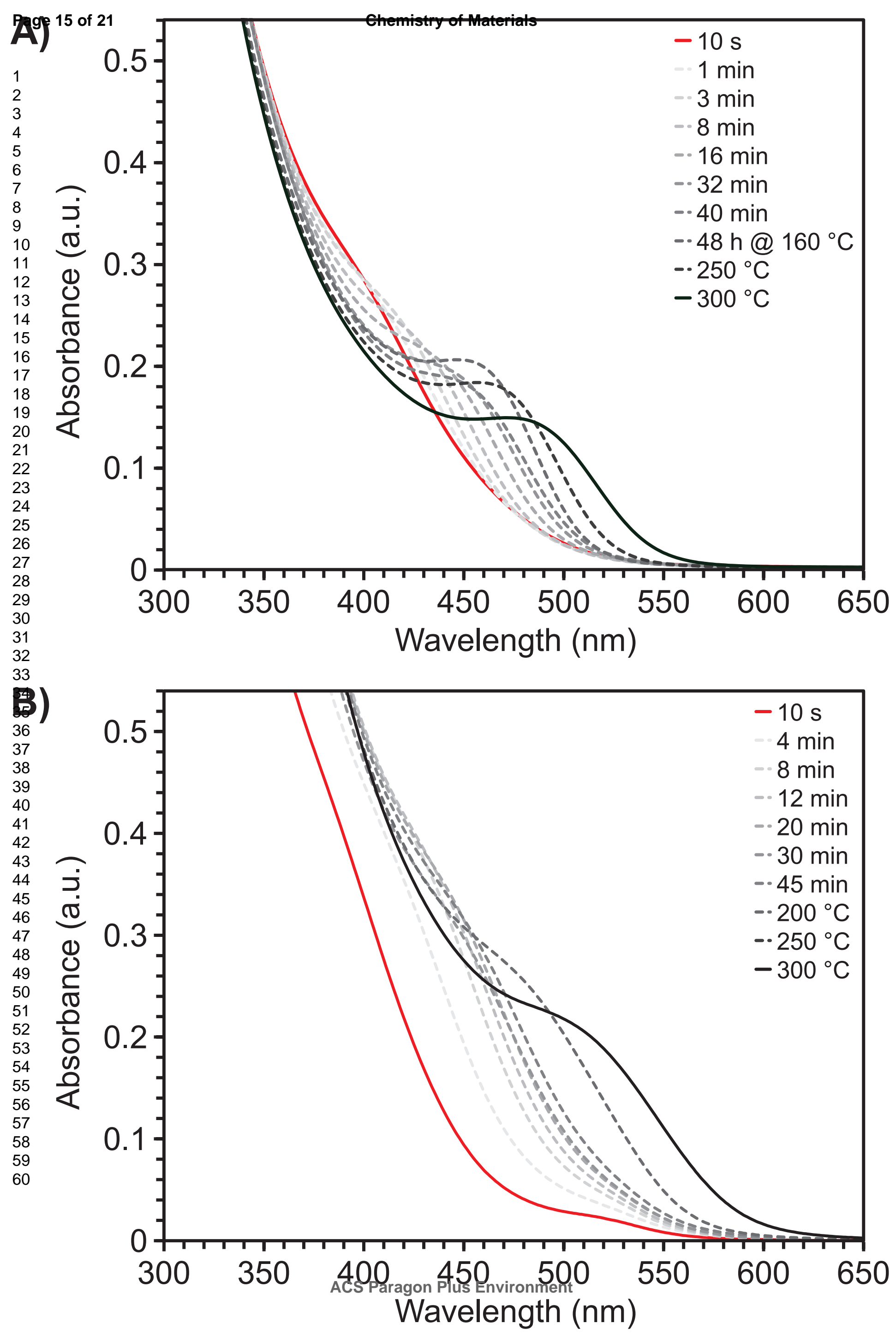

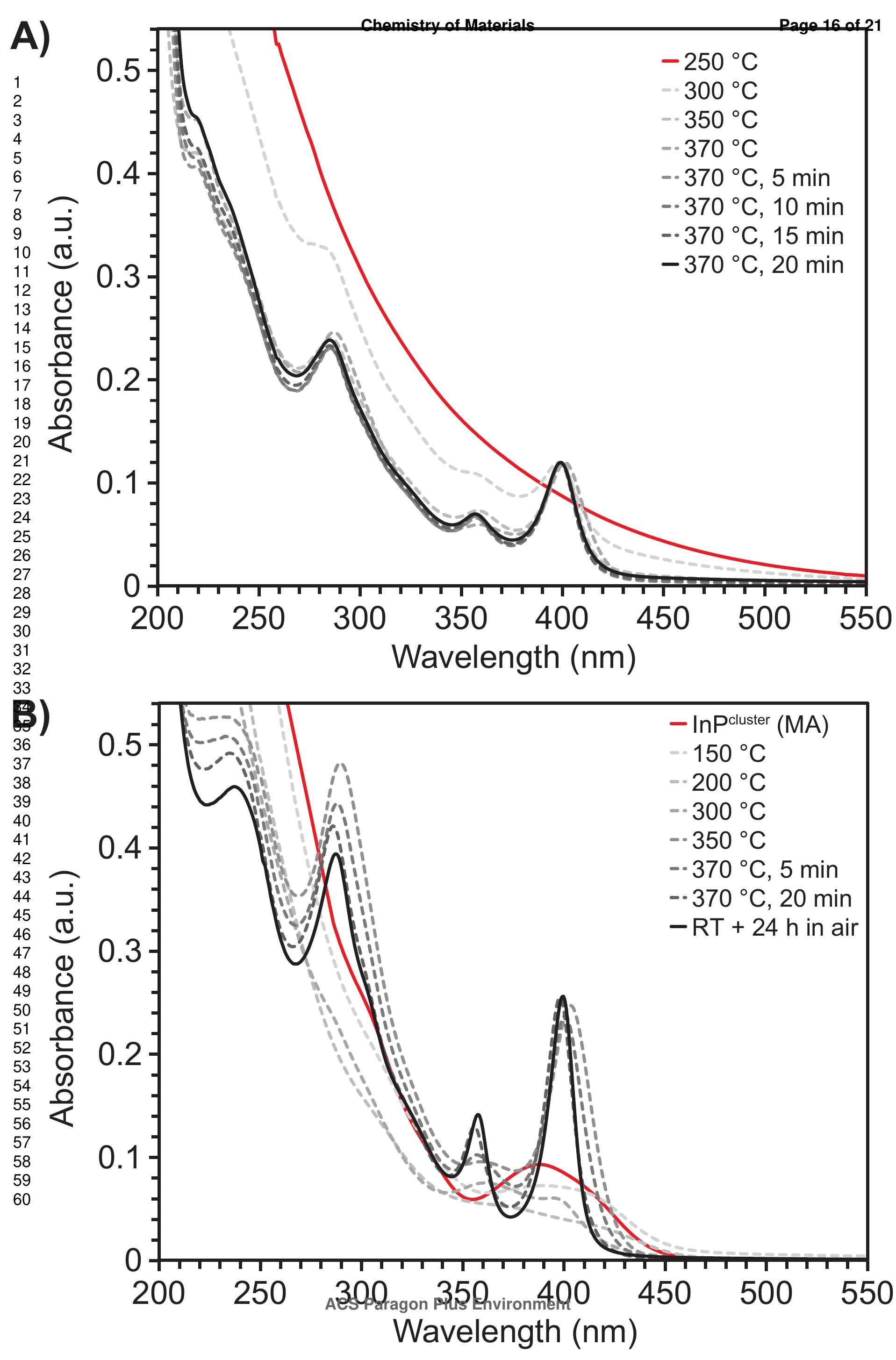


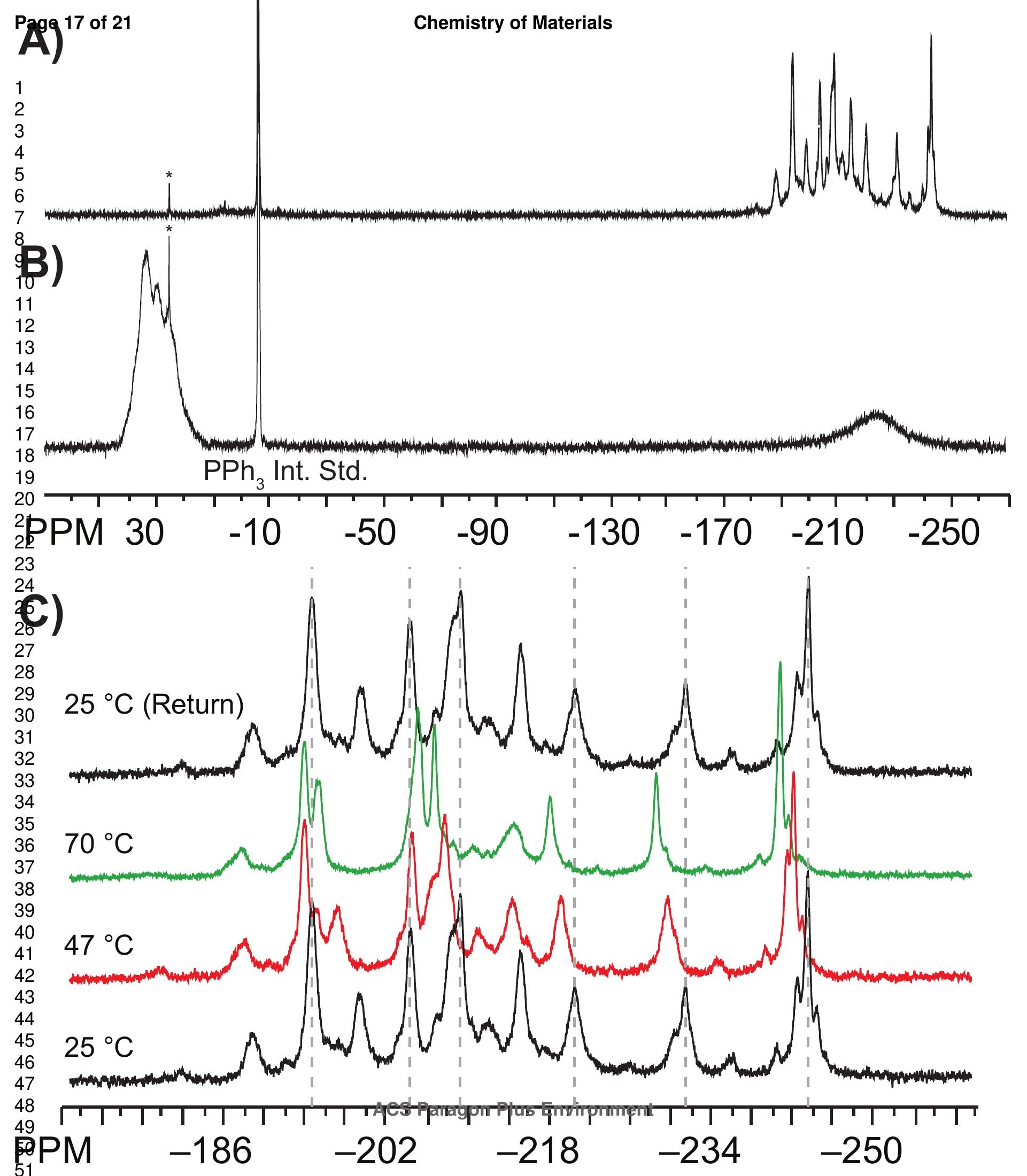




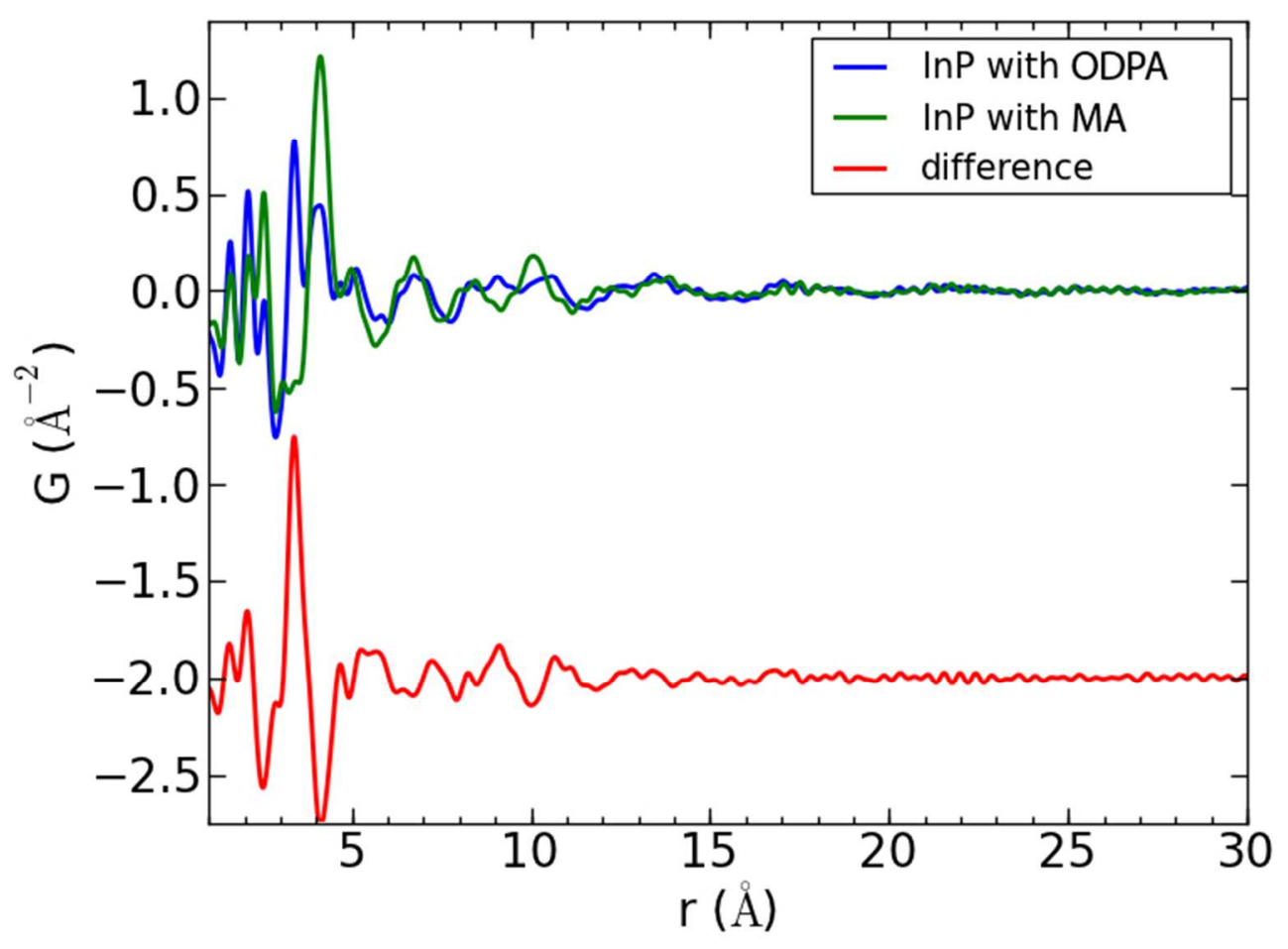

$271 \times 200 \mathrm{~mm}(72 \times 72$ DPI $)$ 


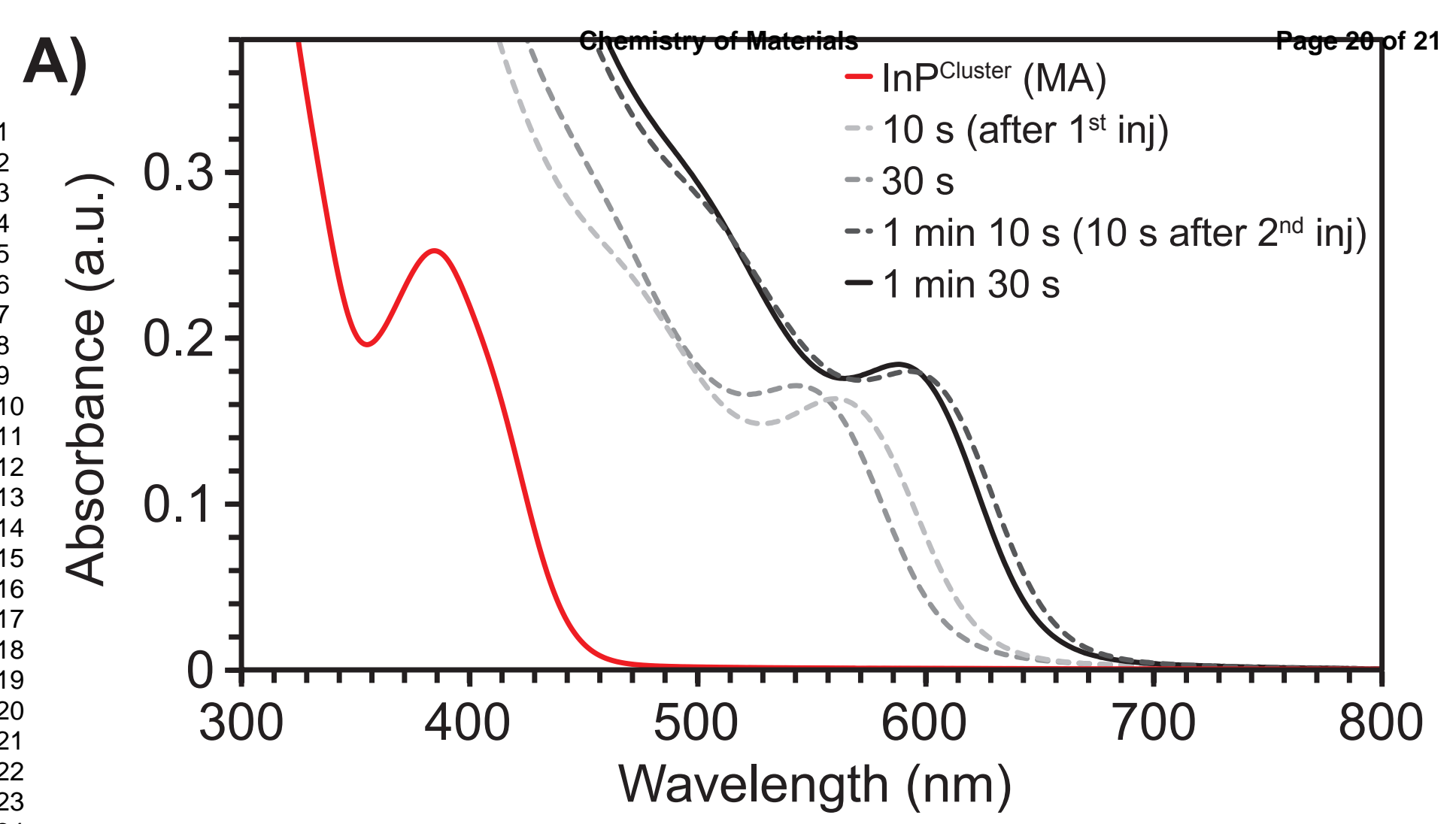

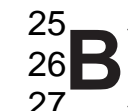

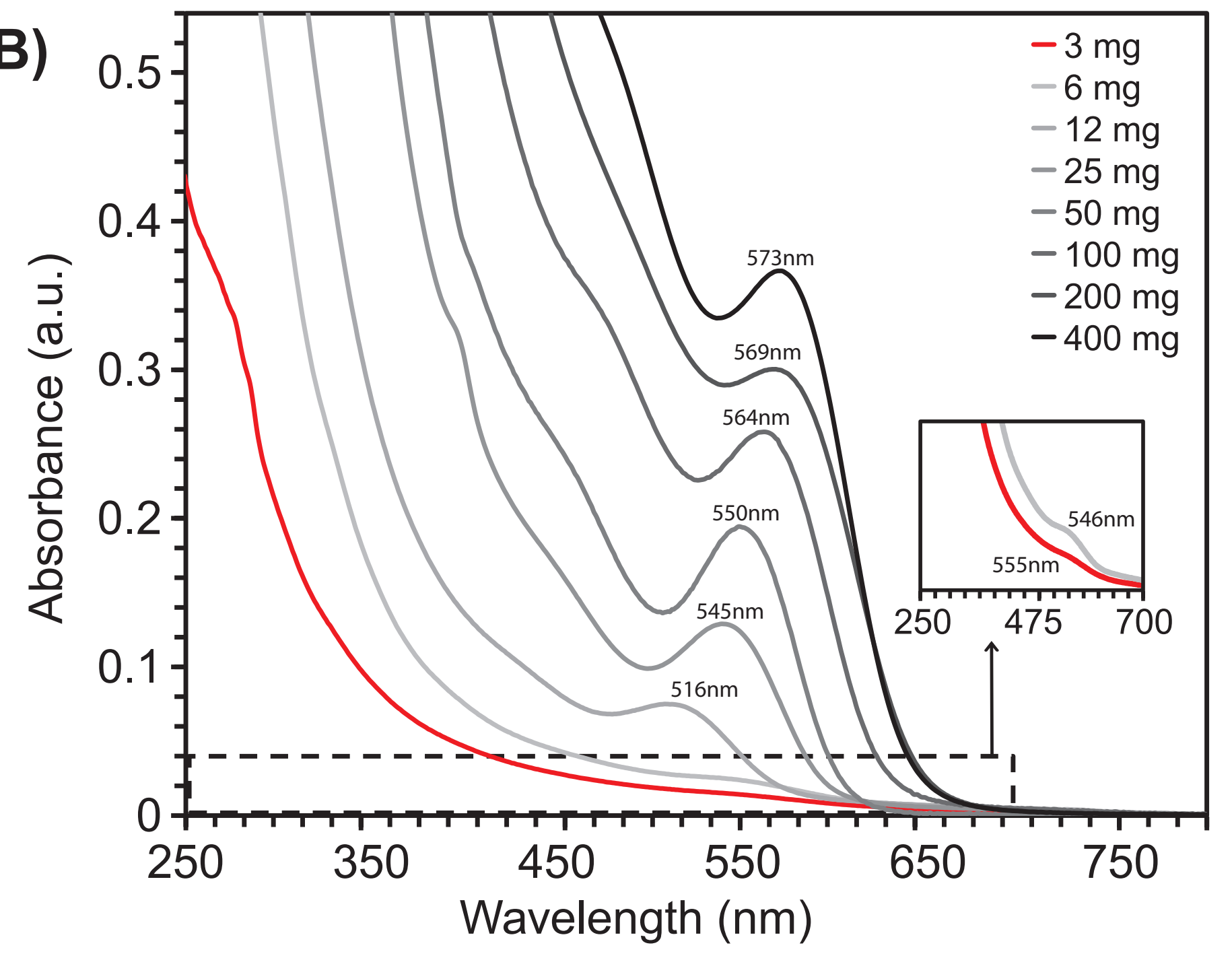

C)

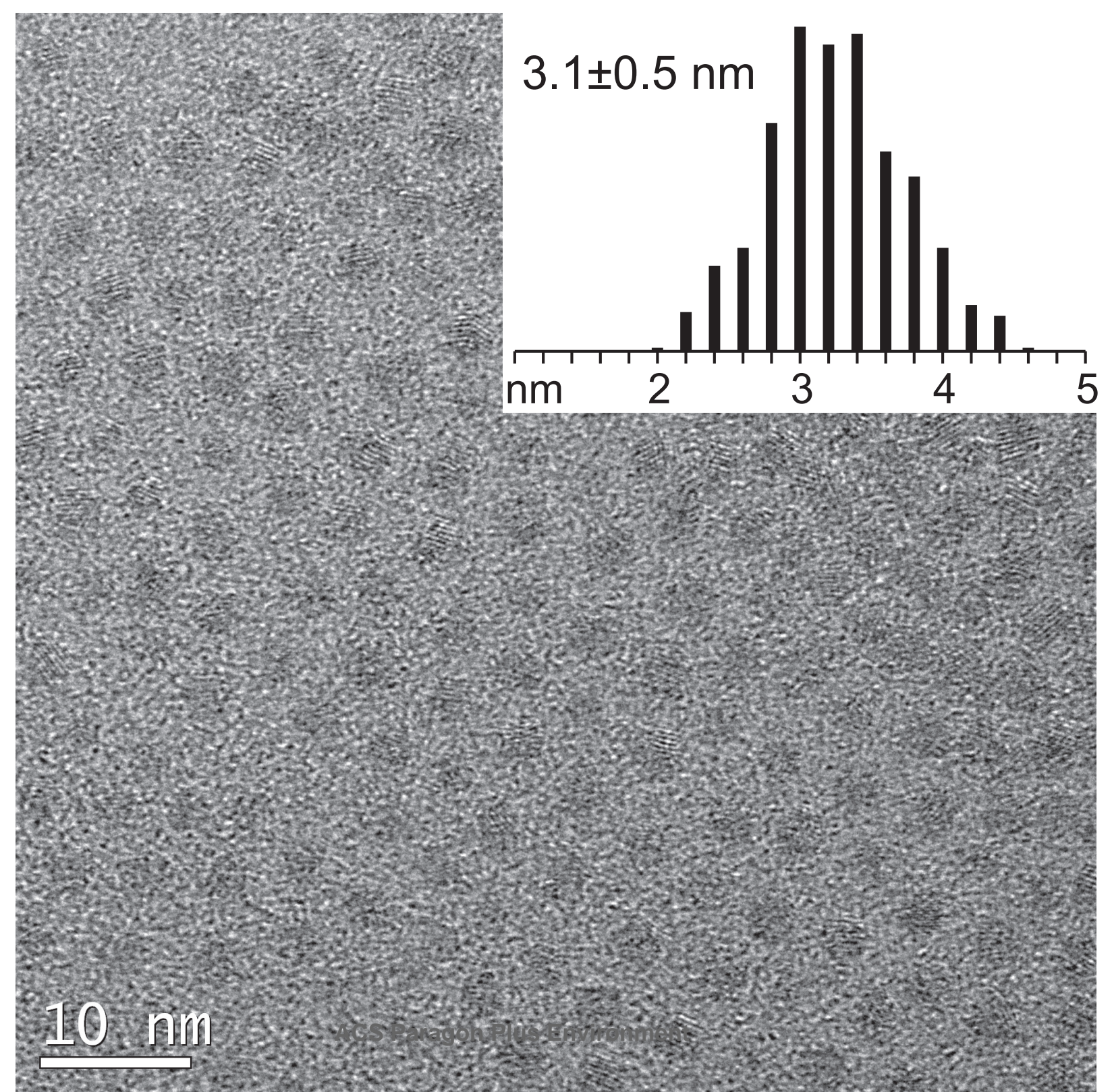


